\title{
The Effect of Organic Acids on the Formation and Behavior of Synthesized Iron Hydroxides: Implications for Acid Mine Drainage Treatment
}

Marianne A. Mannix

Follow this and additional works at: https://researchrepository.wvu.edu/etd

\section{Recommended Citation}

Mannix, Marianne A., "The Effect of Organic Acids on the Formation and Behavior of Synthesized Iron Hydroxides: Implications for Acid Mine Drainage Treatment" (2015). Graduate Theses, Dissertations, and Problem Reports. 6157.

https://researchrepository.wvu.edu/etd/6157

This Thesis is protected by copyright and/or related rights. It has been brought to you by the The Research Repository @WVU with permission from the rights-holder(s). You are free to use this Thesis in any way that is permitted by the copyright and related rights legislation that applies to your use. For other uses you must obtain permission from the rights-holder(s) directly, unless additional rights are indicated by a Creative Commons license in the record and/ or on the work itself. This Thesis has been accepted for inclusion in WVU Graduate Theses, Dissertations, and Problem Reports collection by an authorized administrator of The Research Repository @ WVU. For more information, please contact researchrepository@mail.wvu.edu. 
The Effect of Organic Acids on the Formation and Behavior of Synthesized Iron Hydroxides:

\title{
Implications for Acid Mine Drainage Treatment
}

\author{
Marianne A. Mannix \\ Thesis submitted to the \\ Davis College of Agriculture, Natural Resources, and Design \\ at West Virginia University
}

in partial fulfillment of the requirements for the degree of

Master of Science in

Plant and Soil Science

Louis M. McDonald (Chair) Ph.D.

Alan Sexstone, Ph.D.

Jeff Skousen, Ph.D.

Dorothy Vesper, Ph.D.

Division of Plant and Soil Sciences

West Virginia University

Morgantown, West Virginia

2015

Keywords: Acid Mine Drainage, Iron, Iron Hydroxides, Organic Matter, Organic Acids 


\section{ABSTRACT \\ The Effect of Organic Acids on the Formation and Behavior of \\ Synthesized Iron Hydroxides:}

\section{Implications for Acid Mine Drainage Treatment}

\section{Marianne A. Mannix}

Acid mine drainage (AMD) is an environmental concern that is well known and studied in West Virginia and other mining regions. This pollution threat can be prevented and mitigated with current mining permitting regulations; however some mine waters require treatment, which generally consists of the neutralization of affected waters, resulting in the precipitation of characteristic 'floc' material. AMD floc consists of hydroxides of heavy metals; predominantly iron. This study simulated AMD treatment practices to evaluate the effects of common environmental controls; namely the presence of organic matter (OM) on the formation and settling behavior of Fe hydroxides with the ultimate goal of the optimization of active AMD treatment. Hydroxides were synthesized through the forced hydrolysis of mixed $\mathrm{FeCl}_{3}$ and organic acid solutions. Organic acids varying in number of carboxylic functional groups to include acetate (a monodentate ligand), malate (a bidentate ligand), and citrate (a polydentate ligand) were used as analogs for OM in surface water. It was hypothesized that the addition of organic acids to the Fe system would promote complexation, and as a result produce fewer iron hydroxides. Hydroxide mass, volume, percent of amorphous hydroxide, compression rate, and soluble iron concentrations throughout the titration were measured. The presence of organic acids led to decreased hydroxide mass, increased hydroxide volume, and less pronounced compression after settling. The solubility experiments showed that $\mathrm{OM}$ in solution allowed precipitation at lower than expected $\mathrm{pH}$ values, and allowed for redissolution of $\mathrm{Fe}$ at high $\mathrm{pH}$, suggesting that $\mathrm{OM}$ hinders hydroxide crystallization. 


\section{Acknowledgements}

I would like to acknowledge all of those who have inspired, assisted in, and encouraged the completion of this thesis.

First, I would like to express my gratitude to my advisor, Dr. Louis McDonald, who fostered my interests and provided invaluable guidance throughout my time at WVU. Next, I would like to thank my committee members; Dr. Dorothy Vesper, Dr. Alan Sexstone, and Dr. Jeff Skousen, as well as the professors I studied under during my time at West Virginia University; for broadening my knowledge and inspiring further learning. I would also like to acknowledge Joan Wright and Ida Holaskova, who provided invaluable help with lab work and statistical analysis.

I would like to acknowledge Dr. Melanie Szulczewski; who sparked my interest in soil science, and Anne Overstreet; who serves as a career mentor to me -- both of whom are exceptional examples of successful, influential women in science and inspire me to succeed. I would like to thank my colleagues and friends for their help and company, and my family for their unwavering love and encouragement. 


\section{Table of Contents}

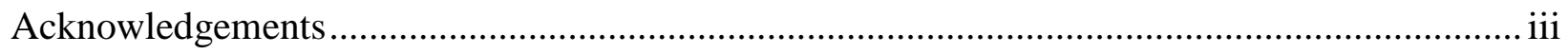

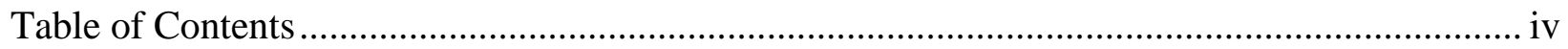

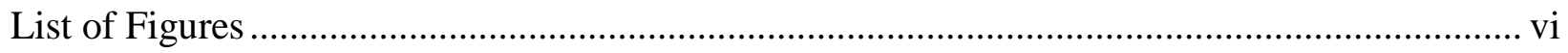

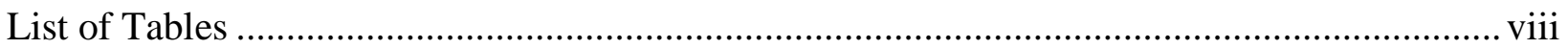

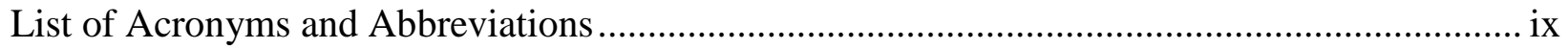

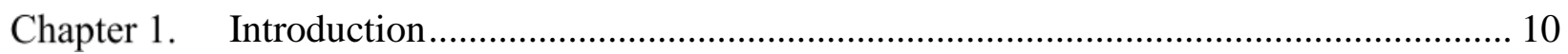

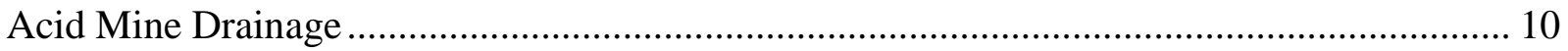

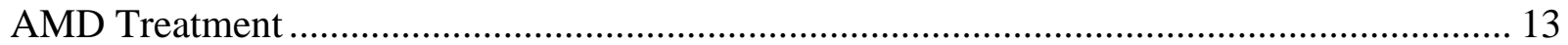

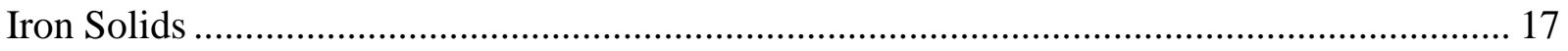

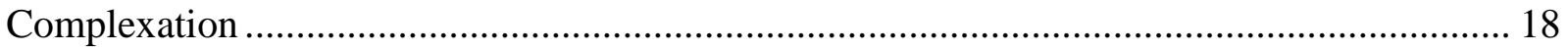

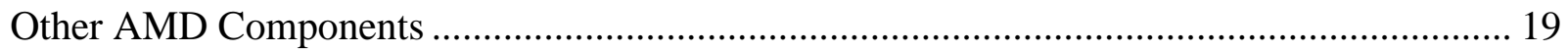

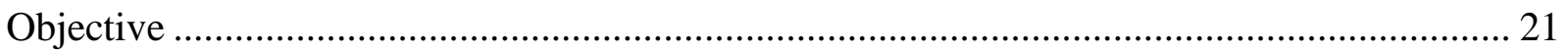

Chapter 2. Materials and Methods................................................................................. 23

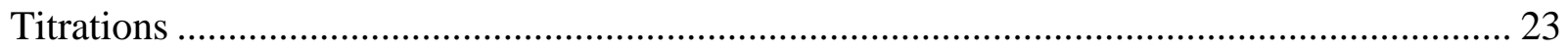

Effect on Dissolved Fe Concentration ....................................................................... 23

Effect on Hydroxide Floc Behavior ....................................................................... 24

Data Fitting and Statistical Analysis ......................................................................... 26

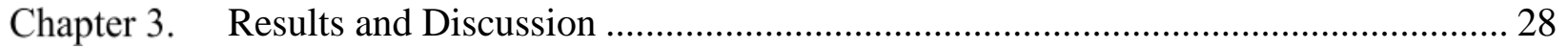


Effects on Dissolved Fe Concentration

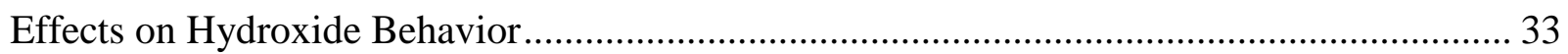

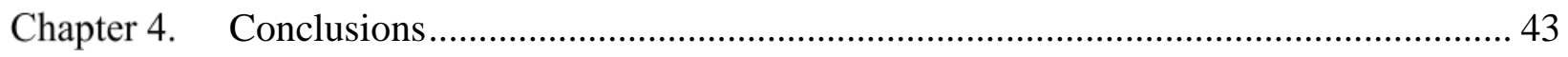

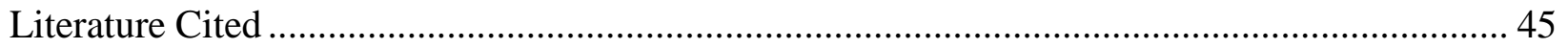

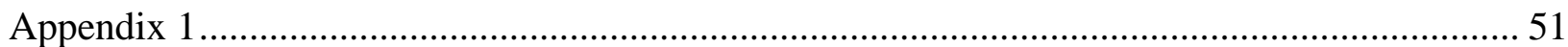




\section{List of Figures}

Figure 1.1. Schematic representation of typical AMD reactions.

Figure 1.2. Distribution of iron, iron hydroxide complexes and total dissolved iron in equilibrium with $\mathrm{Fe}(\mathrm{OH})_{3}$ as a function of $\mathrm{pH} . \mathrm{I}=0$, Temperature $=25^{\circ} \mathrm{C}$ (Lindsay, 1979)...... 15

Figure 3.1. Titration curves for $\mathrm{FeCl}_{3}, \mathrm{FeCl}_{3}+$ Acetic Acid, $\mathrm{FeCl}_{3}+$ Malic Acid, and $\mathrm{FeCl}_{3}+$ Citric Acid Systems. Data points represent pH after base addition. Horizontal lines represent pKa values for each organic acid.

Figure 3.2. Total dissolved Fe concentrations $(\mathrm{mg} / \mathrm{L})$ in solutions of $\mathrm{FeCl}_{3}$ and low, medium, and high concentrations of acetic acid as a function of $\mathrm{pH}$ 30

Figure 3.3. pH at minimum Fe concentration for acetic, malic, and citric acids. 30

Figure 3.4. Soluble Fe concentrations (mg/L) as determined through ICP analysis in solutions of $\mathrm{FeCl}_{3}$, and low, medium, and high concentrations of malic acid as a function of $\mathrm{pH}$.

Figure 3.5. Soluble Fe concentrations (mg/L) as determined through ICP analysis in in solutions of $\mathrm{FeCl}_{3}$, and low, medium, and high concentrations of citric acid as a function of $\mathrm{pH}$.

Figure 3.6. Hydroxide compression during the first hour of settling; represented by the settled volume of hydroxides in each treatment solution as a function of time the solids were allowed to settle in the Imhoff cones after formation.

Figure 3.7. Rate of hydroxide compression in each organic acid and the control solutions (determined using time as a covariate in ANCOVA and comparing regression slopes for the three organic acids). Error bars represent standard error. $\mathrm{df}=3$. 35 
Figure 3.8. Least square means for the volumes $(\mathrm{mL})$ of settled hydroxide material (squared) in each organic acid treatment compared to the control $\left(\mathrm{FeCl}_{3}\right)$ Error bars represent standard error

Figure 3.9. Least square means for the masses (mg) of settled hydroxide material (squared) in each organic acid treatment compared to the control $\left(\mathrm{FeCl}_{3}\right)$. Error bars represent standard error.

Figure 3.10. Density $\mathrm{mg} / \mathrm{mL}$ calculated from final settled mass and final settled volume data... 40

Figure 3.11. Percent of amorphous Fe hydroxides formed in the $\mathrm{FeCl}_{3}$, acetic, malic, and citric solutions. Error bars represent standard error.

Figure A1.1. Fractional concentrations of acetic acid as a function of solution $\mathrm{pH}$ (Sillen et al, 1964).

Figure A1.2. Fractional concentrations of malic acid as a function of solution pH (Sillen et al, 1964)

Figure A1.3. Fractional concentrations of citric acid as a function of solution $\mathrm{pH}$ (Sillen et al, 1964) 


\section{List of Tables}

Table 1.1. Properties of select organic ligands (Sillén et al, 1964). ....................................... 21

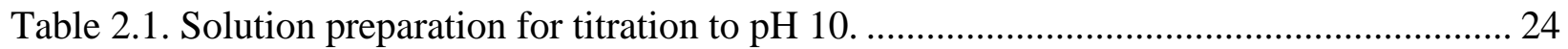

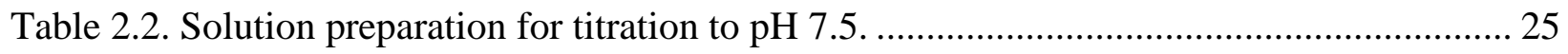

Table 3.1. ANOVA outputs for the main effects of the organic acid in solution, the concentration level of each organic acid, and the interaction between organic acid and concentration level on the final settled volume of hydroxides. ................................................ 36

Table 3.2. ANOVA outputs for the main effects of the organic acid in solution, the concentration level of each organic acid, and the interaction between organic acid and concentration level on the final settled mass of hydroxides. 38 


\section{List of Acronyms and Abbreviations}

\begin{tabular}{|c|c|}
\hline AMD & Acid Mine Drainage \\
\hline AML & Abandoned mine land \\
\hline ANCOVA & Analysis of Covariance \\
\hline ANOVA & Analysis of Variance \\
\hline сср & Cubic close packed \\
\hline CWA & Clean Water Act \\
\hline EPA & Environmental Protection Agency \\
\hline $\mathrm{Fe}$ & Iron \\
\hline $\mathrm{FeS}_{2}$ & Pyrite \\
\hline g & Gram \\
\hline hcp & Hexagonally close packed \\
\hline $\mathrm{hr}$ & Hour \\
\hline$I$ & Ionic strength \\
\hline $\mathrm{L}$ & Liter \\
\hline meq & Milliquivalents \\
\hline $\mathrm{mg}$ & Milligram \\
\hline Min & Minutes \\
\hline $\mathrm{mL}$ & Milliliter \\
\hline $\mathrm{O}$ & Oxygen \\
\hline $\mathrm{OA}$ & Organic Acid \\
\hline $\mathrm{OH}$ & Hydroxide \\
\hline $\mathrm{OM}$ & Organic matter \\
\hline s & Second \\
\hline SMCRA & Surface Mining Control and Reclamation Act \\
\hline$\mu \mathrm{m}$ & Micrometer \\
\hline
\end{tabular}




\section{Chapter 1. Introduction}

Coal is a major component of the energy infrastructure of the world. Coal consumption has steadily increased for the past 50 years and in 2011, 1,003 million short tons of coal were consumed for electricity generation (U.S. Energy Information Administration, 2011). Coal mining provides benefits such as energy, jobs, income, and tax revenue to West Virginia and the United States, but is considered a dirty form of energy because of the associated air and water pollution issues. There is potential for water pollution from coal mining during and after extraction, during processing and from the leachates of exposed overburden and tailings. (Younger 2002).

\section{Acid Mine Drainage}

Acid mine drainage (AMD) is the nomenclature for water polluted as a result of coal or metal mining. It is characterized by low $\mathrm{pH}$ and high metal concentrations. The precursor of AMD is pyrite $\left(\mathrm{FeS}_{2}\right)$ which is abundant in rocks that are mined for coal. Pyrite becomes unstable when exposed to water and oxygen from activities like excavation, mixing, and moving of overburden (Eq. 1). When exposed to the atmosphere, chemical weathering occurs, producing sulfate $\left(\mathrm{SO}_{4}{ }^{2-}\right)$, soluble ferrous iron $\left(\mathrm{Fe}^{2+}\right)$, and acid.

$$
\mathrm{FeS}_{2}+\frac{7}{2} \mathrm{O}_{2}+\mathrm{H}_{2} \mathrm{O} \leftrightarrow 2 \mathrm{Fe}^{2+}+2 \mathrm{SO}_{4}^{2-}+2 \mathrm{H}^{+}
$$

In the presence of dissolved or atmospheric oxygen, the dissolved $\mathrm{Fe}^{2+}$ oxidizes, forming ferric iron $\left(\mathrm{Fe}^{3+}\right)$ and consuming acidity (Eq. 2).

$$
\mathrm{Fe}^{2+}+\frac{1}{4} \mathrm{O}_{2}+\mathrm{H}^{+} \leftrightarrow \mathrm{Fe}^{3+}+\frac{1}{2} \mathrm{H}_{2} \mathrm{O}
$$

The resulting $\mathrm{Fe}^{3+}$ then either reacts further with pyritic material to produce more acidity and $\mathrm{Fe}^{2+}$ (Eq. 3), 


$$
14 \mathrm{Fe}^{3+}+\mathrm{FeS}_{2}+8 \mathrm{H}_{2} \mathrm{O} \rightarrow 2 \mathrm{SO}_{4}^{2-}+15 \mathrm{Fe}^{2+}+16 \mathrm{H}^{+}
$$

or precipitates as iron hydroxides, one of the most visible effects of AMD; yellow to rusty red solid material that can be suspended in water, settled, or deposited on rocks (Eq. 4)

$$
\mathrm{Fe}^{3+}+3 \mathrm{H}_{2} \mathrm{O} \leftrightarrow \mathrm{Fe}(\mathrm{OH})_{3}+3 \mathrm{H}^{+}
$$

Finally, $\mathrm{Fe}^{2+}$ produced through the reaction between the pyritic material and the newly formed $\mathrm{Fe}^{3+}$ (Eq. 3) is re-oxidized by dissolved oxygen (Eq. 2), continuing the Fe reduction-oxidation cycle. Once all of the oxygen in the system has reacted, any remaining aqueous $\mathrm{Fe}^{3+}$ can precipitate as iron hydroxides (Eq. 4) (Figure 1.1) (Stumm \& Morgan, 1996). A number of bacterial species are present in AMD and are known to promote iron oxidation reactions. The oxidation of $\mathrm{Fe}^{2+}$ is slow at low $\mathrm{pH}$, however bacteria such as Acidithiobacillus ferrooxidans and Acidithiobacillus thiooxidans catalyze these reactions, thus iron oxidation and acid production occur (Eq.2) (Jones, et al., 2015; Evangelou, 1998).

AMD is a threat to human health and the environment. Affected streams are typically devoid of aquatic plant life and cannot support fish or other aquatic organisms. AMD impaired drinking water has a distinct bitter taste and can have a laxative effect due to the potentially toxic levels of trace metals (Johnson \& Hallberg, 2005). If left untreated, AMD can persist for hundreds of years. 


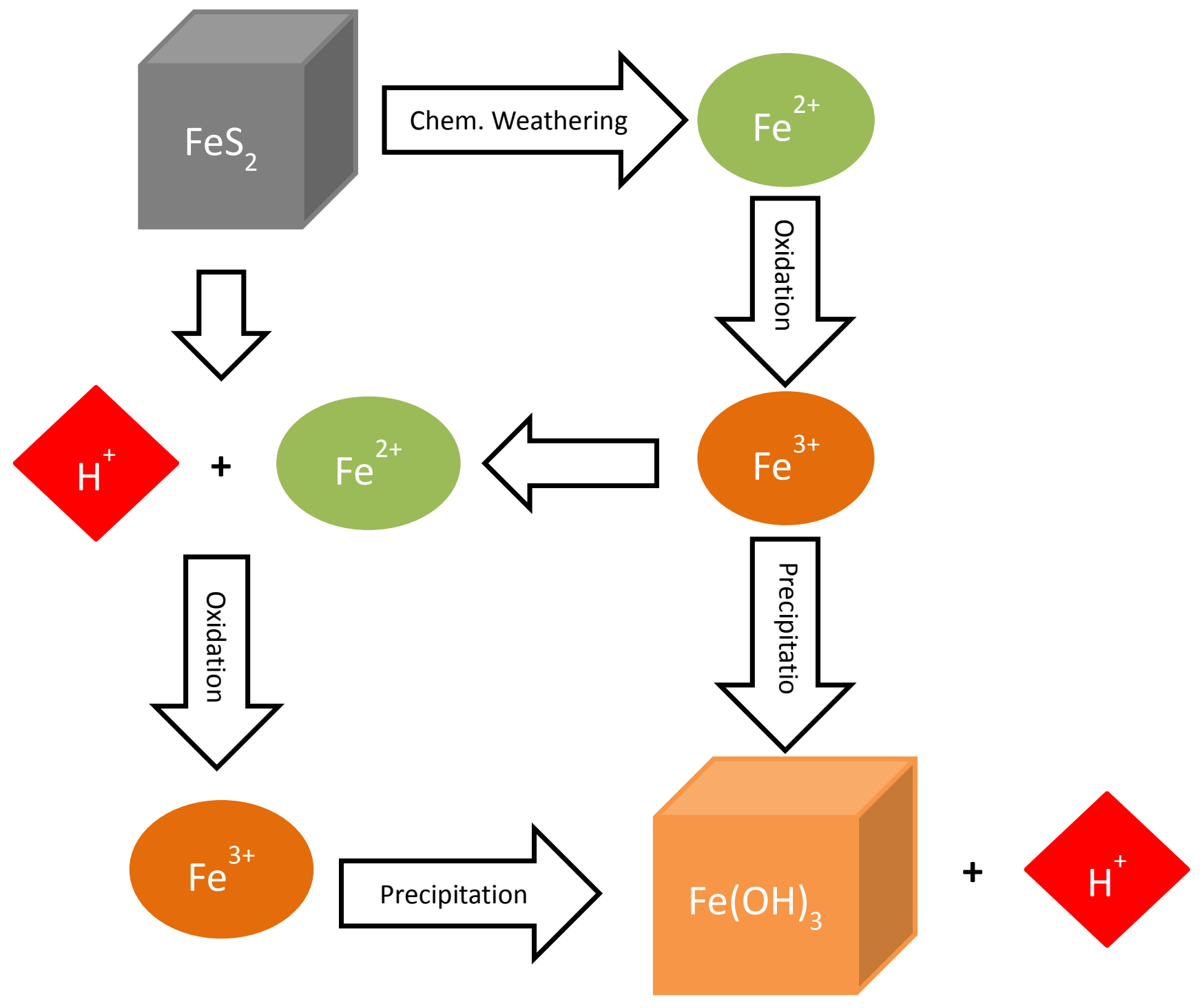

Figure 1.1. Schematic representation of typical AMD reactions. 


\section{$\underline{\text { AMD Treatment }}$}

In 1977, the Surface Mining Control and Reclamation Act (SMCRA) the first federal regulation requiring coal companies to restore land post mining and the Clean Water Act (CWA) which established our country's pollution discharge permitting system were established (Rosenbaum, 2011). These regulations aid in the control of mining pollution, but are limited in their protection of abandoned coal mine lands (AML). AML's are sites which ceased operation before SMCRA was enacted, and typically produce the most AMD due to the absence of regulation and legal accountability for water treatment. Current EPA water quality standards mandate that wastewater not exceed Fe concentrations of $0.3 \mathrm{mg} / \mathrm{L}$ and the $\mathrm{pH}$ is stabilized between 6 and 9 before being re-introduced into the environment (Evangelou, 1998). These standards can be met through a variety of AMD treatment methods.

The main processes involved in AMD treatment are the oxidation of metals, acidity neutralization, and sedimentation and subsequent excavation of hydroxides; most notably Fe hydroxides (Younger, 2002). Passive treatment mimics natural processes to remediate unfavorable characteristics of polluted water. Metals precipitate out of solution, and the $\mathrm{pH}$ rises as a result of mixing with uncontaminated water, neutralization by naturally occurring alkaline material, or by alkalinity produced through microbial processes (Younger, 2002). Passive treatment is best suited for treating sites with low flow and low metal concentrations (Skousen et al., 2002; Trumm, 2010). The three predominant types of passive treatment systems are inorganic media passive systems such as oxic or anoxic limestone beds, wetland-type passive systems which can be aerobic or anaerobic, and sulfate reducing bioreactors (Younger, 2002). Once passive systems are implemented, they can typically operate autonomously, making them an excellent option for closed or abandoned mine sites. Additional advantages to passive treatment include relatively low 
operating costs, low maintenance, and the naturally-occurring and therefore nonhazardous nature of the materials used.

Sites with very high metal concentrations are difficult to treat passively because an influx of metal concentrations and/or high flow rates could overwhelm the system, resulting in the release of excess untreated wastewater into the environment (Younger, 2002). These type of sites often require active treatment technologies to reach discharge limits. Active AMD treatment technologies perform the same AMD treatment processes described above. AMD is oxidized; allowing metal ions to be transformed to their less soluble counterparts through aeration, biochemical oxidation or bacterial oxidation. Alkaline material such as sodium hydroxide $(\mathrm{NaOH})$, sodium carbonate $\left(\mathrm{Na}_{2} \mathrm{CO}_{3}\right)$, calcium hydroxide $\left(\mathrm{Ca}(\mathrm{OH})_{2}\right)$, and ammonia $\left(\mathrm{NH}_{3}\right)$ raise the solution $\mathrm{pH}$; thus neutralizing acidity and promoting hydroxide formation. The hydroxides formed through AMD treatment are referred to as 'floc' or sludge.

Comparatively, active treatment generally yields a larger volume of hydroxides than passive treatment methods due to the highly polluted nature of the wastewater and those hydroxides settle through coagulation and flocculation in ponds or clarifers (Younger, 2002). Retention time of the hydroxides in settling ponds is dictated by the formation rate and settling velocity of Fe hydroxide particles. Active AMD treatment plans are selected on a site-to-site basis and should be determined by characteristics of AMD at the site and the desired effluent characteristics. Sites with high flow, low pH, high metal concentrations, ongoing mining operations, land area constraints, and where operators are available are optimal for active AMD treatment (Skousen et al., 2002; Trumm, 2010). 
Aqueous Iron Chemistry

Iron $\left(\mathrm{Fe}^{3+}\right)$ is the primary element of concern in AMD. The solubility of iron minerals is dependent on $\mathrm{pH}$ with a characteristic U-shaped solubility curve; it is soluble at low and high $\mathrm{pH}$, and insoluble at neutral and circumneutral $\mathrm{pH}$ (Figure 1.2). At near neutral $\mathrm{pH}$ in equilibrium with $\mathrm{Fe}(\mathrm{OH})_{3}, \mathrm{Fe}^{3+}$ precipitates out of solution forming a number of insoluble ferric hydroxide species (Fujii et al., 2009). In general, iron hydroxide precipitation is lowest at pH values of 4 and 12, and greatest at $\mathrm{pH}$ 7-8.

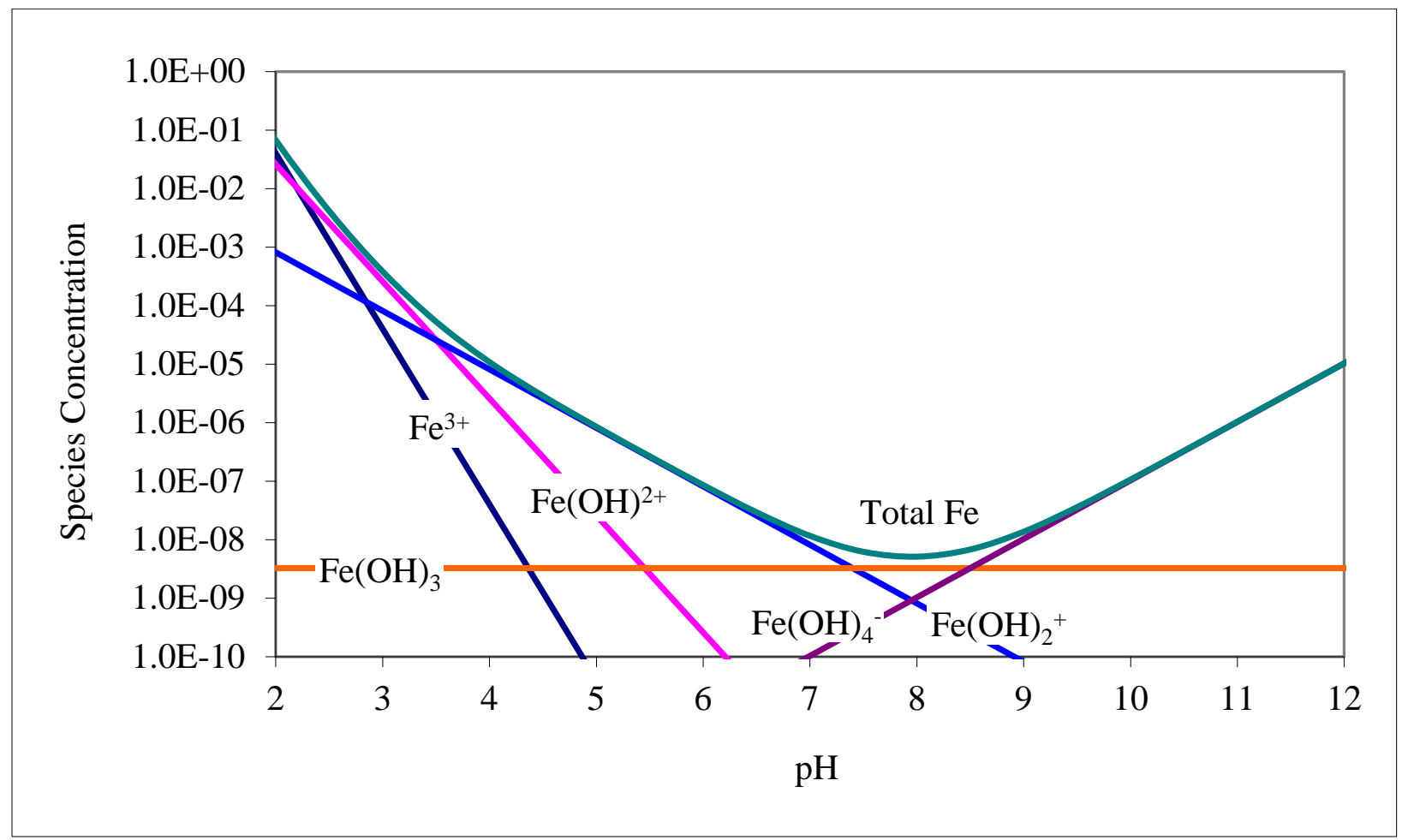

Figure 1.2. Distribution of iron, iron hydroxide complexes and total dissolved iron in equilibrium with $\mathrm{Fe}(\mathrm{OH})_{3}$ as a function of $\mathrm{pH} . \mathrm{I}=0$, Temperature $=25^{\circ} \mathrm{C}$ (Lindsay, 1979).

Fe hydroxides precipitate out of solution through hydrolysis and nucleation reactions. Hydrolysis can be achieved through base additions to an acidic Fe salt solution or by increasing the temperature of solution. Stable Fe hydroxides that form through this process can be crystalline 
or amorphous depending on solution characteristics (Schwertmann, 1991; Cornell et al, 1989). Cornell and colleagues (1989) assert that the variable having the most influence on the rate of hydroxide formation is $\mathrm{pH}$.

The $\mathrm{Fe}^{3+}$ hydrolysis process breaks down the octahedrally coordinated hydrated ion structure of iron by sequential elimination of $\mathrm{H}^{+}$ions until a stable hydroxide crystal structure forms. Simplified equations for hydrolysis (Stumm \& Morgan, 1996) can be represented as:

$$
\begin{array}{lr}
\mathrm{Fe}^{3+}+\mathrm{H}_{2} \mathrm{O} \leftrightarrow \mathrm{Fe}(\mathrm{OH})^{2+}+\mathrm{H}^{+} & \log \mathrm{K}=-3.05 \\
\mathrm{Fe}^{3+}+2 \mathrm{H}_{2} \mathrm{O} \leftrightarrow \mathrm{Fe}(\mathrm{OH})_{2}^{+}+2 \mathrm{H}^{+} & \log \beta{ }_{2}=-6.31 \\
\mathrm{Fe}^{3+}+3 \mathrm{H}_{2} \mathrm{O} \leftrightarrow \mathrm{Fe}(\mathrm{OH})_{3}^{0}+3 \mathrm{H}^{+} & \log \beta_{3}=-13.8 \\
\mathrm{Fe}^{3+}+4 \mathrm{H}_{2} \mathrm{O} \leftrightarrow \mathrm{Fe}(\mathrm{OH})_{4}^{-}+4 \mathrm{H}^{+} & \log \beta_{4}=-22.7
\end{array}
$$

These reactions assume that there are no other ligands in solution.

Nucleation forms a number of compounds including low molecular weight complexes, hydrolytic polymers, and precipitated hydroxides (Feng and Nansheng, 2000). As individual hydroxide crystals age, they have the potential to transform into larger, more ordered, and more dense Fe hydroxides. Crystal nucleation can be affected by $\mathrm{pH}$, temperature, and ionic strength, and can be inhibited in the presence of organic matter, phosphate, and silicate species (Schwertmann, 1991).

The general process of hydroxide precipitation can be described as follows. Crystal nuclei (low-molecular-weight monomer and dimer Fe hydroxides) form from hydrolysis reactions. Eventually, the monomers and dimers aggregate and form larger, polynuclear polymers. These hydroxides generally aggregate until all of the Fe in solution is incorporated (Cornell et al, 1989). 
Once the polymers are large enough, precipitation and settling occurs (Cornell et. al, 1989; Dousma and de Bruyn, 1976).

Fe hydroxides become less reactive and more ordered over time, with Fe centers becoming more coordinated through dissolution-precipitation reactions and rearrangement (Bligh and Waite, 2010). In one study, it was proposed that dissolution-precipitation reactions lead to greater coordination of Fe centers because those of lesser coordination preferentially redissolve (Bligh and Waite, 2010). After precipitation, Fe hydroxides aggregate, forming large clusters which effectively reduces the amount of surface area available for reaction. Trace concentrations of Fe in solution can react with newly formed Fe hydroxides to produce more hydroxides (Bligh and Waite, 2010).

\section{$\underline{\text { Iron Solids }}$}

Iron oxides have an octahedral structure comprised of two tetrahedra made up of six oxygen ions $(\mathrm{O})$ or some combination of $\mathrm{O}$ and hydroxide $(\mathrm{OH})$ ions surrounding the coordinating Fe ion. Fe oxides can have hexagonally close packed (hcp) or cubic close packed (cсp) structure. Oxides with hep structure are known as $\alpha$-phase and ccp oxides are called $\gamma$-phase (Schwertmann, 1991). $\alpha$-phase Fe oxides are more stable. Of the 13 known Fe oxides, hydroxides, and oxyhydroxides, hematite, goethite, lepidocrocite, magnetite, maghemite, ferrihydrite, and schwertmannite are commonly found in nature, however only schwertmannite and ferrihydrite are likely to form in AMD scenarios (Schwertmann, 1991). Hematite and goethite are $\alpha$-phase Fe oxides and are the most stable, followed by lepidocrocite, maghemite, and magnetite ( $\gamma$-phase). Ferrihydrite is the least stable of the aforementioned iron oxides (Loeppert \& Inskeep, 1996). 
Some Fe solids can be repurposed and used in science and industry (Zboril et al., 2002). These high quality hydroxides can be used as pigments, in bricks and concrete, as soil amendments, reagents, and have the potential to transform into economically valuable ores such as hematite, magnetite, and maghamite (Cui et al., 2013). The bulk of AMD sludge has little economic value and is expensive to excavate and/or haul to landfills or holding locations. This problematic sludge has low density and is comprised of up to 95\% water. In order to decrease the costs associated with disposal, operators can mix a majority of the sludge with incoming AMD, providing nuclei for further Fe hydroxide formation and reducing the water content to 80-85\% (Younger, 2002). Other processes such as storing sludge material in dry impoundments and allowing it to drain, vacuum filtration, continuous pressure dewatering, frame and plate pressing, and centrifuge separation have been applied to Fe hydroxide sludge to reduce the water content even further, as low as 20$50 \%$ to make disposal more feasible and cost effective (Younger, 2002). The optimization of AMD treatment chemistry could be beneficial in managing AMD sludge in an environmentally friendly and economically beneficial manner.

\section{Complexation}

Metals, such as Fe have the capacity to form covalent bonds with ligands. A ligand can replace water in the hydration sphere of a metal by donating an electron pair (Stumm and Morgan, 1991). The compound that forms when a ligand occupies the space that water once did is called a complex. Fe ions can act as Lewis acids (Eq. 5) and unshared electron pairs in the valance shell of the Fe ions are attracted to water, and pull electrons out of the surrounding water molecule's O-H orbitals (Eq. 5), weakening those bonds, and making $\mathrm{H}^{+}$ions in the water molecule dissociate more easily (Benjamin, 2002). Chelation is the formation of a very strong complex with a bi- or polydentate ligand (one that contains two or more donor groups and forms more than one bond with 
the metal ion). Ligands also readily adsorb onto the surface of $\mathrm{Fe}^{3+}$ minerals (surface complexation) and bond via oxygen donor atoms (Jones, et al., 2009a). Aqueous and surface complexes are stronger for polydentate ligands than for monodentate ligands.

Both dissolved aqueous and surface complexes can affect Fe hydroxide precipitation. Aqueous complexes increase total dissolved $\mathrm{Fe}$ concentrations, decrease $\mathrm{Fe}^{3+}$ concentrations (activity) and thus inhibit precipitation (Jones et al., 2009a). This phenomenon can manifest itself as a marked increase in dissolved iron concentrations at near neutral to high $\mathrm{pH}$ were it is otherwise insoluble (Stumm and Morgan, 1996; Sholkovitz and Copeland, 1980). Surface complexes weaken metal-oxygen bonds in the crystal lattice, promoting dissolution, depending on the strength of the complex. Adsorbed ligands stabilize some hydroxides against rearrangement, impeding crystal nucleation and growth by eliminating the crystal nuclei (Cornell et al, 1989; Jones, A. et al., 2009b).

\section{Other AMD Components}

The hydrolysis, nucleation, and complexation processes described above are simplified and assume relatively simple solutions; however, acid mine drainage is a dynamic solution with many other components. Two components that have received little to no attention are sulfate and dissolved organic matter (OM).

Sulfate is major constituent in AMD as sulfur is a component of pyrite (Evangelou, 1998). Lenter et al. (2002) evaluated the effects of sulfate in solution, the neutralizing base used, and the neutralization $\mathrm{pH}$ on the formation and settling behavior of synthesized Fe hydroxides. It was observed that the Fe:SO 4 ratio was the variable that most affected hydroxide properties. The hydroxide sludge formed in solutions with a high $\mathrm{Fe}: \mathrm{SO}_{4}$ ratio had slower settling rates, larger 
volumes and took significantly longer to reach the total suspended solids discharge limit (Lenter, 2002). Another study suggested that $\mathrm{SO}_{4}{ }^{-}$anions compete with $\mathrm{OH}^{-}$anions for surface sites, hindering the formation of hydroxides and their subsequent transformation into more stable iron

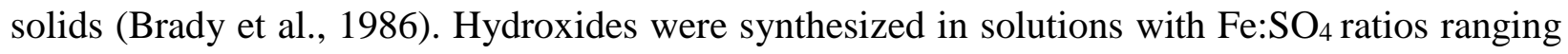
from $0-1.8$. The solutions were dialyzed to simulate hydroxide aging for up to 30 days. The amount of sulfate in solution ultimately affected the amount and type of hydroxide that formed. At

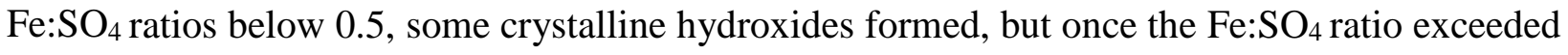
1.5, only weakly crystalline hydroxides (ferrihydrite and feroxyhydrite) were able to form (Brady, et al., 1986).

Dissolved organic matter $(\mathrm{OM})$ is present in all natural surface waters as a consequence of runoff and leaching from soils and from biological processes in sediments and the water column, at concentrations up to $20 \mathrm{mg} / \mathrm{L}$ (Rashid, 1972). Dissolved organic molecules could vary in size (e.g. molecular weight, molar volume) from relatively simple organic acids, soluble sugars and proteins, to the more structurally complex extracellular polysaccharides, humic and fulvic acids. They could also vary in metal reactivity from non-reactive non-polar molecules to the very reactive polar molecules. Those compounds with polar properties could have a range in the type and number of metal reactive functional groups, primarily amines and carboxylic acids.

In AMD the primary sources of dissolved OM are likely the result of biological processes including living and dead bacteria (e.g. Acidithiobacillus ferrooxidans and Acidithiobacillus thiooxidans) and their metabolic wastes and exudates, decomposed plant material and root exudates from passive AMD treatment systems (e.g. wetlands and sulfate reducing bioreactors). Abiotic sources of OM could include soluble organic components from coal and shales disturbed in the mining process. Dissolved OM can be expected to affect AMD treatment by promoting 
dissolution, inhibiting precipitation, or facilitating electron transfer (Sparks, 2003; Lahann, 1976; Walte and Morel, 1984).

\section{Objective}

The objective of this study was to determine the effects of $\mathrm{OM}$ on the formation and behavior of Fe hydroxides in fully oxidized systems. To simplify and isolate the processes involved a series of relatively simple organic acids (acetate, malate and citrate) were chosen as OM analogs. These were selected because they allowed for a systematic variation in the number of carboxyl functional groups and acid-base character (Table 1.1, Appendix 1). The effects on soluble Fe concentration, final settled hydroxide volume, final settled hydroxide mass, hydroxide compression over time, and rate of compression were determined.

Table 1.1. Properties of select organic ligands (Sillén et al, 1964).

\begin{tabular}{|c|c|c|c|c|c|}
\hline $\begin{array}{l}\text { Organic } \\
\text { Acid }\end{array}$ & Formula & Structural Diagram & $\begin{array}{l}\text { Molecular } \\
\text { Weight }\end{array}$ & $\begin{array}{l}\text { Complexation } \\
\text { Constant }\end{array}$ & $\mathrm{pKa}$ \\
\hline Citric & $\mathrm{C}_{6} \mathrm{H}_{8} \mathrm{O}_{7}$ & & 192.12 & $\mathrm{Fe}^{3+}: 11.5^{*}$ & $\begin{array}{l}\mathrm{pKa}_{1}: 3.14 \\
\mathrm{pKa}_{2}: 4.75 \\
\mathrm{pKa}_{3}: 6.39\end{array}$ \\
\hline Malic & $\mathrm{C}_{4} \mathrm{H}_{6} \mathrm{O}_{5}$ & $\mathrm{HO}^{\circ}$ & 134.09 & $\mathrm{Fe}^{3+}: 7.1^{*}$ & $\begin{array}{l}\mathrm{pKa}_{1}: 3.40 \\
\mathrm{pKa}_{2}: 5.20\end{array}$ \\
\hline Acetic & $\mathrm{C}_{2} \mathrm{H}_{4} \mathrm{O}_{2}$ & ค & 60.05 & $\mathrm{Fe}^{3+}: 3.38^{*}$ & $\mathrm{pKa}_{1}: 4.76$ \\
\hline
\end{tabular}

*The stability constants are as listed assuming $20^{\circ} \mathrm{C}$ and $0.1 \mathrm{~atm}$.

All of these factors have the potential to influence AMD treatment practices; whether it be the type, cost, or duration of treatment. Understanding the role OM plays in the formation and 
behavior of iron hydroxides during the treatment process could enable operators to act appropriately to save time, money, and most importantly to ensure adequate treatment of mine polluted water before discharge into the environment. 


\section{Chapter 2. Materials and Methods}

Two sets of titrations were performed; one to determine the effect of organic acids on dissolved iron concentration, titration to $\mathrm{pH} 10$, and another to determine the effect of organic acids on the hydroxide floc behavior, titration to $\mathrm{pH}$ 7.5.

\section{$\underline{\text { Titrations }}$}

All titrations were performed with stock solutions of $1 \mathrm{mmol} / \mathrm{L} \mathrm{FeCl}$, acetic acid, malic acid, and citric acid. The solutions were prepared by adding measured $\mathrm{FeCl}_{3}$ salts, glacial acetic acid, solid malic acid powder, and solid citric acid powder and distilled deionized water to glass volumetric flasks. The titrant used for all titrations was $0.2 \mathrm{~N}$ sodium hydroxide $(\mathrm{NaOH})$.

Titrations were carried out by hand using a Mettler Toledo Seven Easy pH meter with a Mettler Toledo In Lab ${ }^{\circledR}$ Expert Pro $\mathrm{pH}$ electrode. Before each titration the electrode was standardized with Fisher Scientific pH 2.00, 4.01, and 7.00 buffers. All solutions were stirred on Fisher Scientific Isotemp Stirring Plates at $350 \mathrm{rpm}$ for the entirety of the titration. Titrant was added in small increments $(0.01-2.5 \mathrm{~mL}$ ) with Eppendorf Reference Auto Pipettes until the desired endpoint was achieved. Each titration was performed in duplicate.

\section{Effect on Dissolved Fe Concentration}

To evaluate the effect of organic acids on dissolved iron concentration, titrations were conducted to an endpoint of $\mathrm{pH} 10$. The titration solutions were prepared by combining a set amount $(5,15$, or $25 \mathrm{~mL})$ of $1 \mathrm{mmol} / \mathrm{L}$ organic acid stock solution to $300 \mathrm{~mL}$ of $1 \mathrm{mmol} / \mathrm{L} \mathrm{FeCl}_{3}$ stock solution so that the ratio of Fe to OA was constant (Table 2.1). The control solution was 300 $\mathrm{mL}$ of the $\mathrm{FeCl}_{3}$ stock solution. The volume of each $\mathrm{NaOH}$ addition was recorded along with the resulting $\mathrm{pH}$ of the iron-organic acid solution. Aliquots were taken before, throughout, and after 
each titration, filtered through Whatman 42 filter papers ( $2.5 \mu \mathrm{m}$ pore size) and collected in $15 \mathrm{~mL}$ FisherBrand polystyrene disposable centrifuge tubes for ICP determination of total dissolved Fe concentrations.

Table 2.1. Solution preparation for titration to $\mathrm{pH} 10$.

\begin{tabular}{lllll}
\hline Solution & Treatment Level & $\begin{array}{l}\text { Volume of } \mathrm{FeCl}_{3} \\
\text { Solution }\end{array}$ & $\begin{array}{l}\text { Volume of Organic } \\
\text { Acid Solution }\end{array}$ & Molar Ratio OA:Fe \\
\hline Control & -- & 300 & -- & \\
\hline Acetate & Low & 300 & 5 & -- \\
& Medium & 300 & 15 & 0.017 \\
& High & 300 & 25 & 0.050 \\
\hline Malate & Low & 300 & 5 & 0.083 \\
& Medium & 300 & 15 & 0.017 \\
& High & 300 & 25 & 0.050 \\
\hline Citrate & Low & 300 & 5 & 0.083 \\
& Medium & 300 & 15 & 0.017 \\
& High & 300 & 25 & 0.050 \\
\hline
\end{tabular}

Effect on Hydroxide Floc Behavior

To evaluate the effect of organic acids on hydroxide floc behavior, titrations were conducted to an endpoint of $\mathrm{pH}$ 7.5. The titration solutions were prepared by combining a set amount $(5,45$, or $75 \mathrm{~mL})$ of $1 \mathrm{mmol} / \mathrm{L}$ organic acid stock solution to $900 \mathrm{~mL}$ of $1 \mathrm{mmol} / \mathrm{L} \mathrm{FeCl}_{3}$ stock solution so that the ratio of Fe to OA was constant and consistent with the $\mathrm{pH} 10$ titrations (Table 2.2). The neutralized solution and suspended hydroxides from each titration were deposited into $1 \mathrm{~L}$ Nalgene Imhoff settling cones. The volume of floc in each Imhoff cone was observed and 
recorded as it settled to the bottom of the cone at 15 minute increments for the first hour. The final volume was recorded after four hours. The entire suspension was then filtered through Nalgene ${ }^{\circledR}$ Filter Holders with Receivers using pre-weighed $0.45 \mu \mathrm{m}$ Pall Life Sciences Metricel membrane filter papers to collect all Fe precipitates. The hydroxides were covered and air dried mass recorded by subtracting the initial mass of the filter paper.

Table 2.2. Solution preparation for titration to $\mathrm{pH} 7.5$.

\begin{tabular}{lllll}
\hline Solution & $\begin{array}{l}\text { Treatment } \\
\text { Level }\end{array}$ & $\begin{array}{l}\text { Volume of } \mathrm{FeCl}_{3} \\
\text { Solution }\end{array}$ & $\begin{array}{l}\text { Volume of Organic } \\
\text { Acid Solution }\end{array}$ & Molar Ratio OA:Fe \\
\hline Control & -- & 900 & -- & -- \\
\hline Organic Acid & Low & 900 & 15 & 0.017 \\
& Medium & 900 & 45 & 0.050 \\
& High & 900 & 75 & 0.083 \\
\hline
\end{tabular}

The percentage of amorphous iron hydroxides was determined through an ammonium oxalate extraction. An ammonium oxalate extraction was performed on all hydroxides collected from the $\mathrm{pH} 7.5$ titrations to determine the amount of amorphous inorganic iron in each sample.

The collected hydroxides were weighed and deposited into disposable $50 \mathrm{~mL}$ centrifuge tubes. $10 \mathrm{~mL}$ of prepared $0.2 \mathrm{M}$ ammonium oxalate solution adjusted to a $\mathrm{pH}$ of 3 was added to each tube, the lids were secured tightly and shaken for four hours at $120 \mathrm{rpm}$ in total darkness. After shaking, all tubes were centrifuged for 20 minutes, filtered through Whatman 42 filter papers, and decanted (Ross and Wang, 1993). Samples were diluted by a factor of 100 and Fe concentration was determined by ICP analysis. The percent of amorphous iron $\left(\% \mathrm{Fe}_{\mathrm{am}}\right)$ was calculated as (Sheldrick, 1984) 


$$
\% \mathrm{Fe}_{\mathrm{am}}=\frac{\left[\mathrm{Fe}^{3+}\right] \times \mathrm{V}_{\mathrm{amox}} \times \mathrm{F} \times 100}{\mathrm{M}_{\mathrm{Feox}} \times 1000}
$$

where,

$$
\begin{aligned}
& {\left[\mathrm{Fe}^{3+}\right]=\text { dissolved iron concentration }\left(\mathrm{mg} \mathrm{L}^{-1}\right) \text {, }} \\
& \mathrm{V}_{\mathrm{amox}}=\text { volume of } 0.2 \mathrm{M} \text { ammonium oxalate solution }(\mathrm{mL}) \text {, } \\
& \mathrm{F}=\text { dilution factor, and } \\
& \mathrm{M}_{\mathrm{Feox}}=\text { mass of iron oxide added }(\mathrm{g})
\end{aligned}
$$

\section{Data Fitting and Statistical Analysis}

Distributions of the final settled volume and final settled mass data were checked for normality using the Shapiro-Wilk test and were determined to deviate from normality. The distributions for settled mass and settled volume were skewed to the left, so the data were squared in order to achieve a more normal distribution. The percent amorphous distribution was skewed slightly to the right, so the data was transformed down the ladder of powers (square root was taken)

The experimental design was a balanced factorial experiment with three treatments (three organic acids (OA) (acetic acid, malic acid, and citric acid), at three treatment levels each (Level) (low, medium, and high concentration). The least square means of final settled mass and final settled volume were determined by two-way analysis of variance (ANOVA) using JMP Pro software by SAS (version 11, SAS Institute, Cary, NC). The main effects of organic acid present, concentration level and the interaction between organic acid and concentration were evaluated. Tukey’s Honest Significant Difference (Tukey’s HSD) test was applied to the resulting data to determine if there were statistically significant differences between the least square means.

$$
\text { Response }(\mathrm{y})=\mu+\mathrm{OA}+\text { Level }+ \text { OA * Level }+\varepsilon
$$


Data associated with Fe-only solutions were analyzed separately because including it would have resulted in an unbalanced factorial design. These data were analyzed by one-way ANOVA using JMP software (version 11, SAS Institute, Cary, NC). All results were compared to the Fe-only data.

Compression rates were determined through Analysis of Covariance (ANCOVA) with time as a covariate using the General Linear Models (GLM) procedure in SAS (version 9.3, SAS Institute, Cary, NC). This analysis was used to determine if there was a significant F value, and then to obtain an estimated slope for each concentration of each organic acid. The main effects of time, concentration (Conc), and the interaction between time and concentration were evaluated.

$$
\text { Parameter }=\mu+\text { Time }+ \text { Conc }+ \text { Time } * \text { Conc }+\epsilon
$$

Tukey’s HSD test was employed to evaluate whether there were statistically significant differences between the least square means. Data associated with Fe-only solutions were analyzed by ANCOVA and the regression procedure in SAS (version 9.3, SAS Institute, Cary, NC). All results were compared to the Fe-only data. 


\section{Chapter 3. Results and Discussion}

\section{Titration Curves}

Plotting base additions in milli-equivalents (meq) against the resulting $\mathrm{pH}$ produced titration curves for each system (Figure 3.1). In general, buffer regions at each pKa line for the organic acids were difficult to discern because either they were too close to the pKa for Fe hydrolysis (malic and citric acids) or because of the difficulty in obtaining a sufficient number of data points when titrating by hand. The exception for this is citric acid where the buffer region associated with $\mathrm{pKa}_{2}$ is evident. Based on the inflection points, the equivalence points for all titrations were 0.71 meq of base with a standard deviation of 0.03 meq.

\section{Effects on Dissolved Fe Concentration}

Plotting ICP determined Fe concentrations against $\mathrm{pH}$ demonstrated the effect of organic acid in solution on the dissolved Fe concentrations in each system. In the acetic acid systems (Figure 3.2), the presence of OM encouraged precipitation at low $\mathrm{pH}$ compared to the control. The acetic high solution reached minimum Fe concentration at the lowest $\mathrm{pH}$ (4.23), followed by the acetic medium solution (4.67), then the acetic low solution (5.99) and finally the control solution (7.49). As acetic acid concentration increased, the $\mathrm{pH}$ of minimum iron concentration decreased. (Figure 3.3). The acetic acid system was the simplest system and the result of decreased $\mathrm{pH}$ at minimum iron concentration with increasing organic acid concentration was straightforward. It is a monoprotic acid, with only one functional group. There was no evidence for complexation, which might be due to the fact that it has the lowest complexation constant of the selected organic acids. 
$\mathrm{FeCl}_{3}$

- pKa Fe^3+

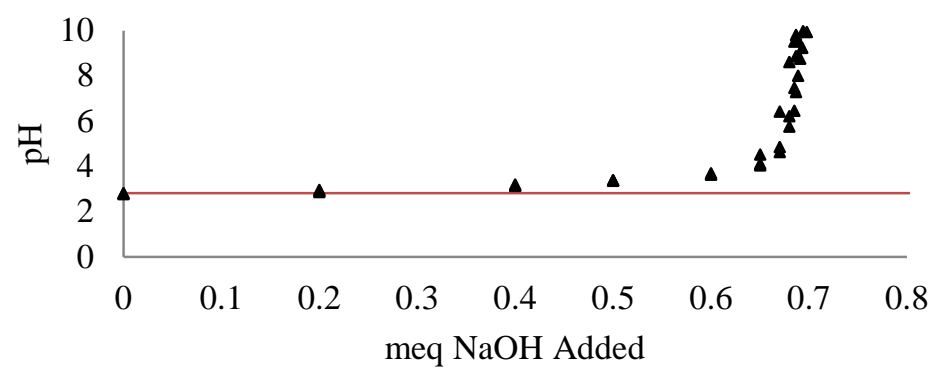

$$
\mathrm{FeCl}_{3}+\text { Malic Acid }
$$

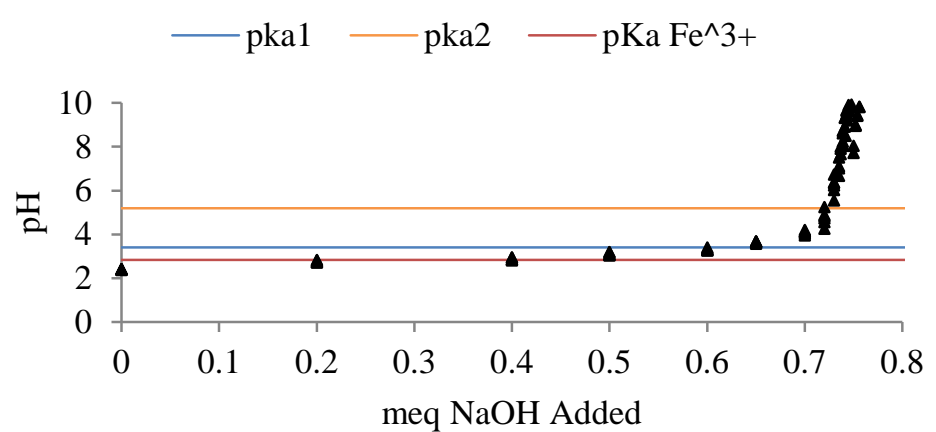

FeCl3 + Acetic Acid

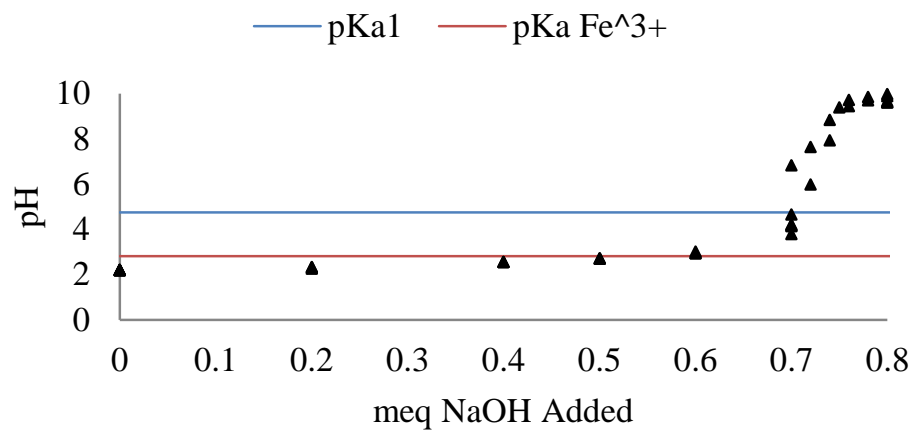

$\mathrm{FeCl}_{3}+$ Citric Acid

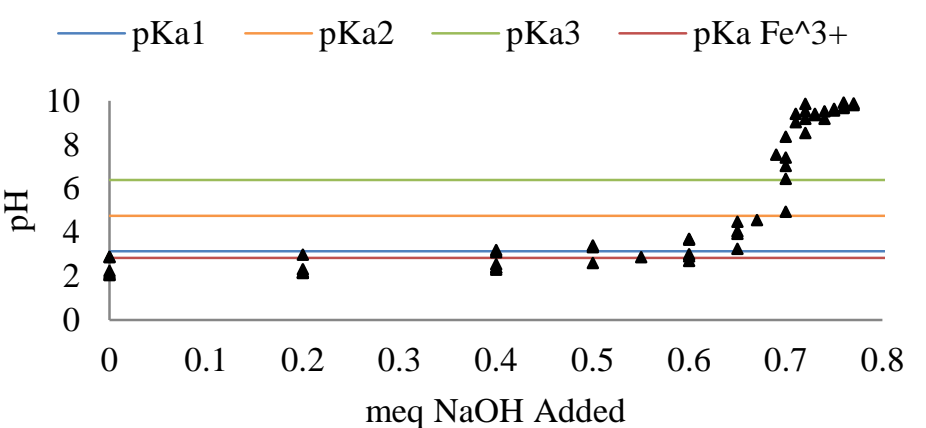

Figure 3.1. Titration curves for $\mathrm{FeCl}_{3}, \mathrm{FeCl}_{3}+$ Acetic Acid, $\mathrm{FeCl}_{3}+$ Malic Acid, and $\mathrm{FeCl}_{3}+$ Citric Acid Systems. Data points represent $\mathrm{pH}$ after base addition. Horizontal lines represent pKa values for each organic acid. 


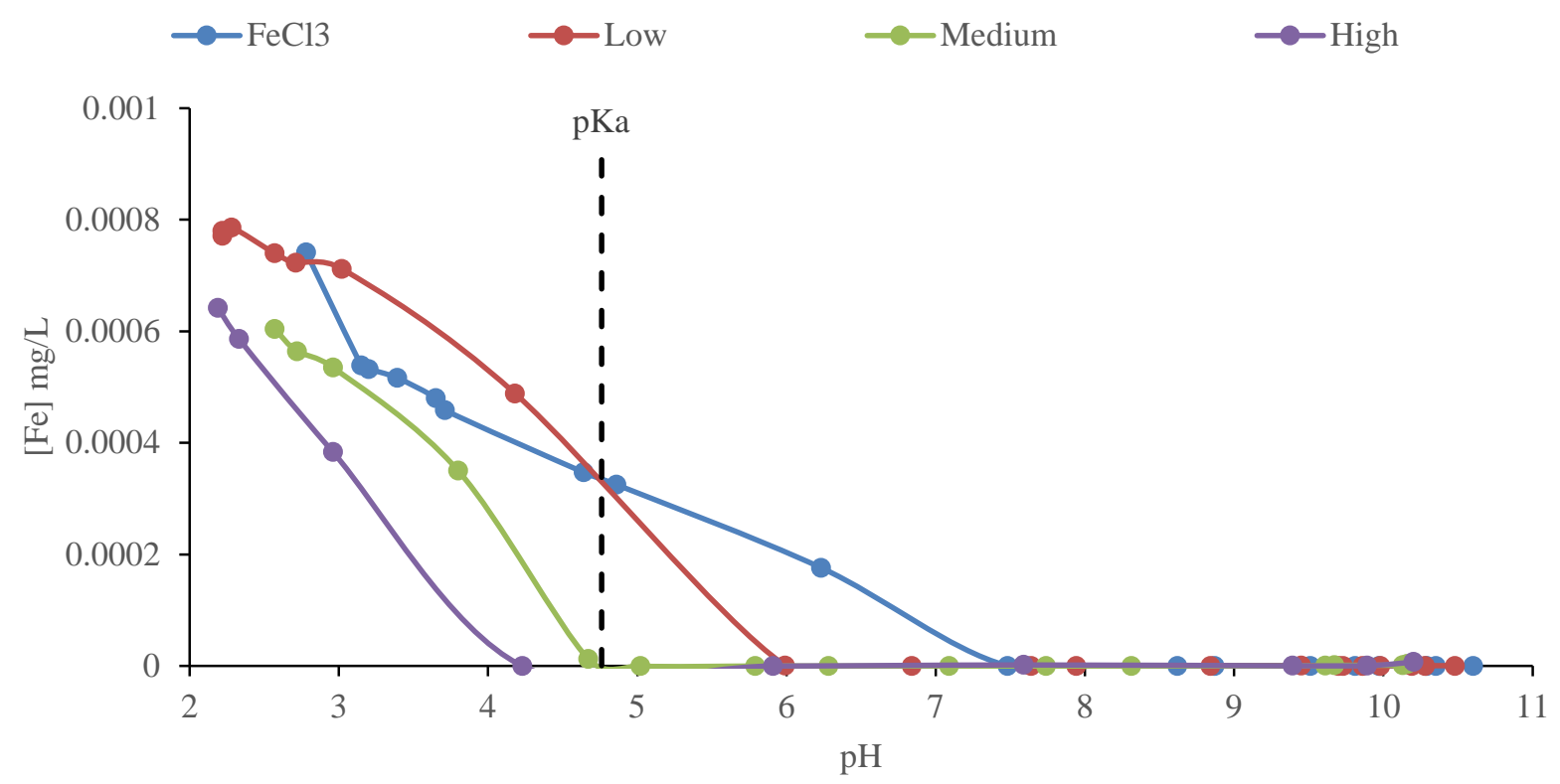

Figure 3.2. Total dissolved Fe concentrations (mg/L) in solutions of $\mathrm{FeCl}_{3}$ and low, medium, and high concentrations of acetic acid as a function of $\mathrm{pH}$.

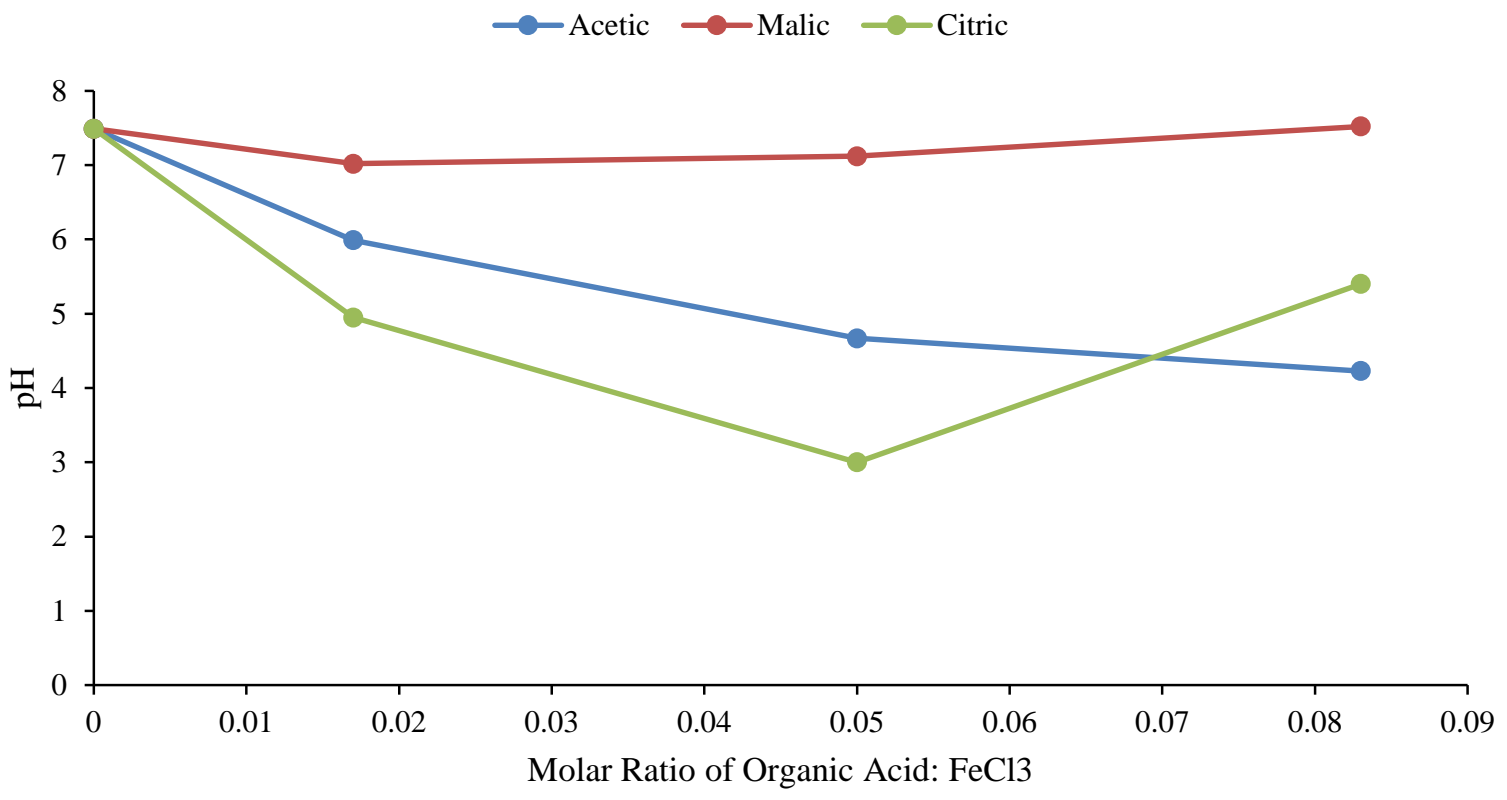

Figure 3.3. pH at minimum Fe concentration for acetic, malic, and citric acids. 
In the malic acid system (Figure 3.4), the rapid precipitation observed in the presence of acetic acid did not occur. Malic acid is a diprotic acid, which makes the system inherently more complex than the monoprotic acetic acid system. This could explain why the earlier precipitation trend was not observed in the malic acid solutions. The malic medium and malic high solutions had higher dissolved Fe concentrations than the control system for the majority of the titration. The malic acid systems reached minimum Fe concentration at similar $\mathrm{pH}$ as the control with precipitation occurring between $\mathrm{pH} 7$ and 8 in all four solutions (Figure 3.3). The increased Fe concentrations suggest that some iron complexation occurred in the malic medium and malic high solutions.

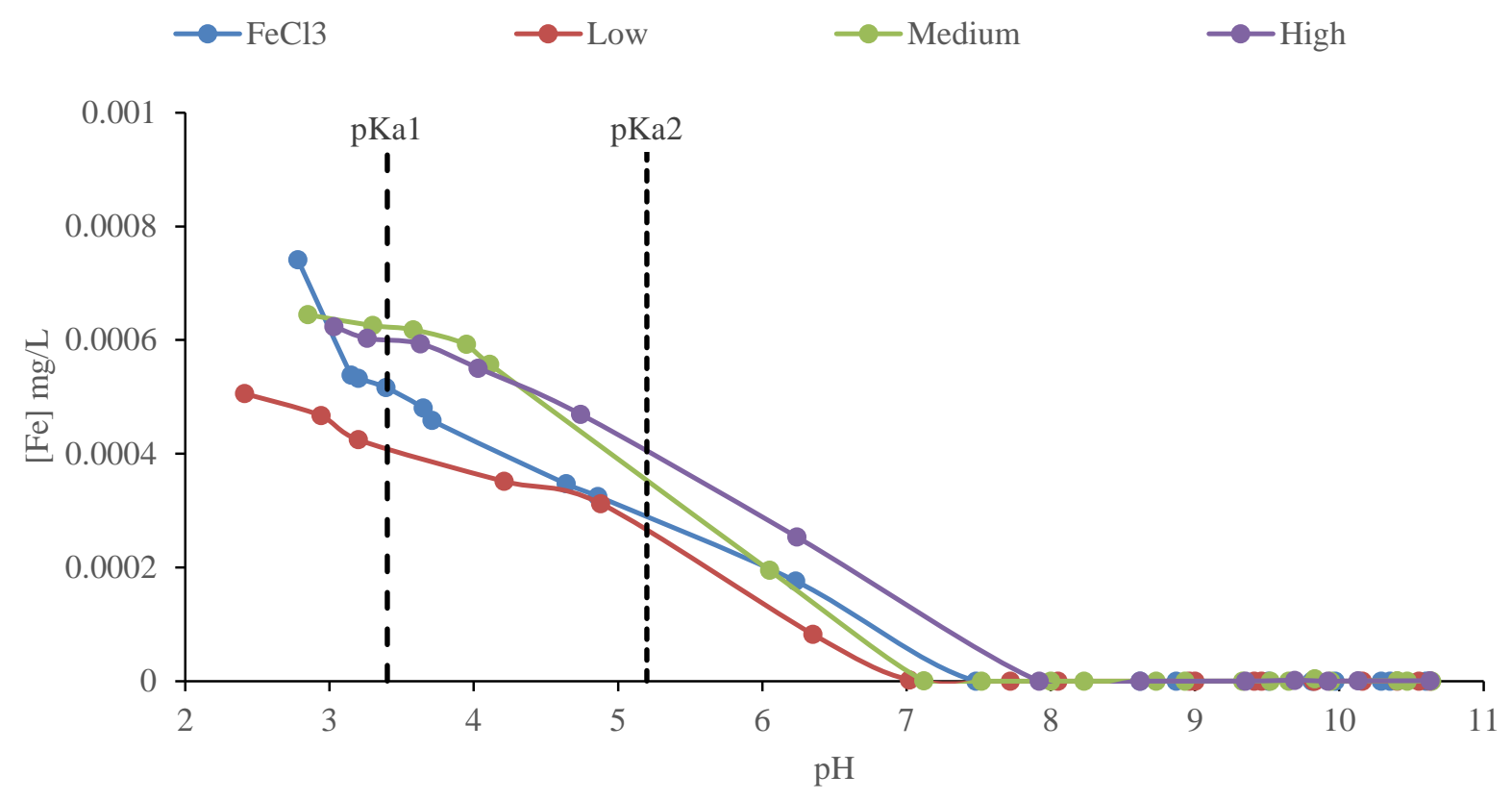

Figure 3.4. Soluble Fe concentrations (mg/L) as determined through ICP analysis in solutions of $\mathrm{FeCl}_{3}$, and low, medium, and high concentrations of malic acid as a function of $\mathrm{pH}$.

Precipitation occurred at lower $\mathrm{pH}$ than the control for all citric acid solutions (Figure 3.5). The citric medium solution reached minimum Fe concentration around $\mathrm{pH}$ 3, and the citric high 
and low solutions reached minimum Fe concentration between $\mathrm{pH} 5$ and 5.5. (Figure 3.3). Dissolved Fe concentrations were considerably larger than the control in the citric acid solutions beyond pH 8 (Figure 3.5). As citric acid concentration increased, dissolved Fe concentrations at high $\mathrm{pH}$ increased. The increased Fe concentrations at high $\mathrm{pH}$ are evidence that complexation occurred in the presence of citric acid. The complexation constant for citric acid is the highest of the three selected organic acids at 11.5, thus any complexes that formed can be expected to be more stable. The triprotic nature of citrate suggests that at any $\mathrm{pH}$ values a number of citrate species could be present adding to the complexity of the citrate solutions.

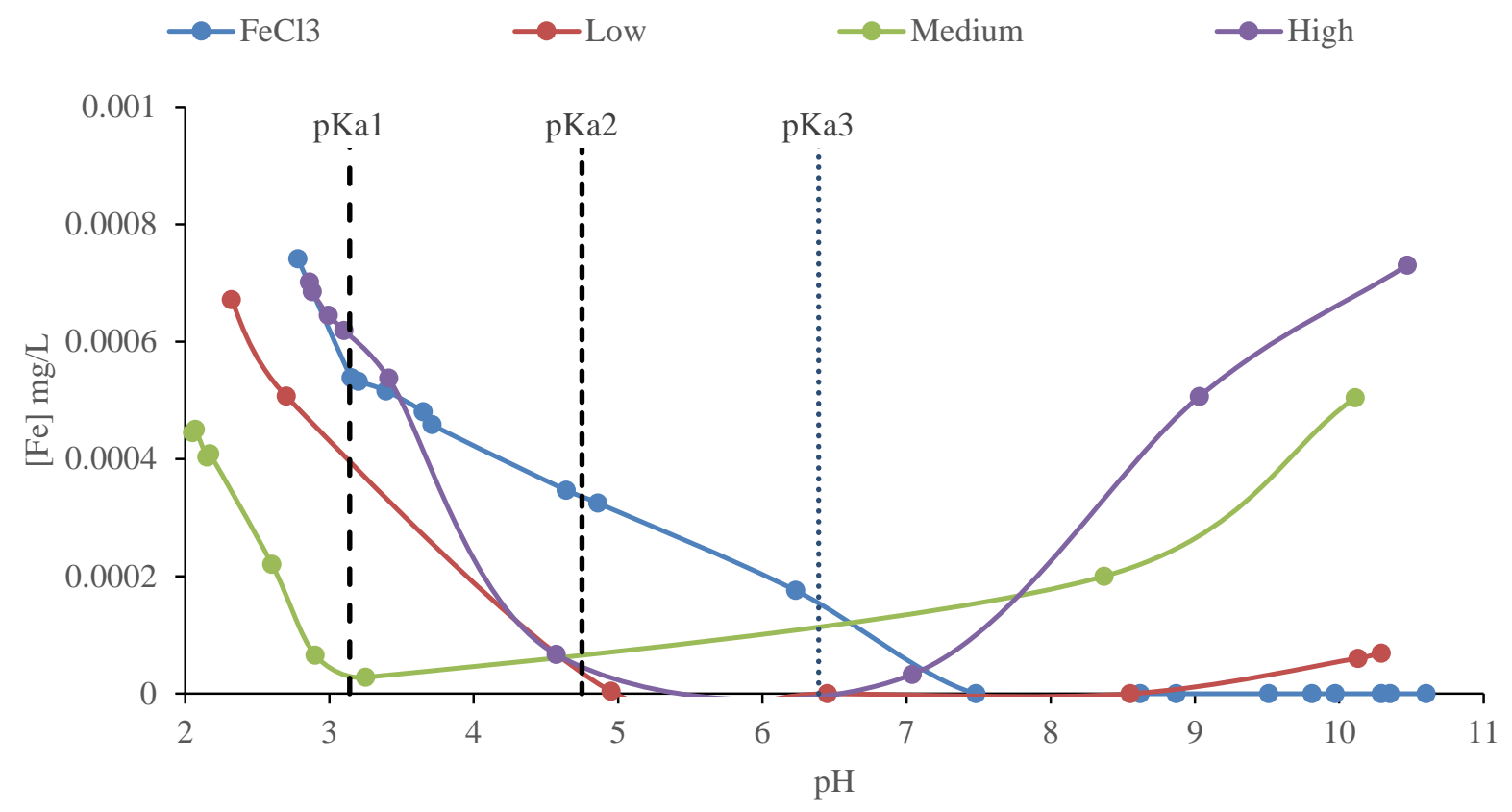

Figure 3.5. Soluble Fe concentrations (mg/L) as determined through ICP analysis in in solutions of $\mathrm{FeCl}_{3}$, and low, medium, and high concentrations of citric acid as a function of $\mathrm{pH}$.

The addition of organic acid solutions to the stock $\mathrm{FeCl}_{3}$ solution could have had an effect on the ionic strength. The equation for ionic strength includes a term for ion charge squared. Since the charge on each organic acid varies as $\mathrm{pH}$ changes, ionic strength would be different depending 
on which organic acid was used. Changing ionic strength would undoubtedly have an effect on the solubility in each system, and could have driven some of the unexpected results in this experiment.

In all cases, the presence of organic acid in solution affected dissolved Fe concentration in one way or another. The literature suggests that organic matter in solution interferes with hydroxide recrystallization and contributes to increased dissolved iron concentrations (Cornell et al, 1989; Sholkovitz and Copeland, 1980). Increased iron solubility increases the biologic availability of iron to plants and organisms.

If organic acid in solution lowers the $\mathrm{pH}$ of precipitation, less base would be required to neutralize the wastewater. This would cut treatment costs and shorten treatment time. Monitoring Fe concentration in addition to $\mathrm{pH}$ throughout the neutralization process would allow operators to make more appropriate base additions.

\section{Effects on Hydroxide Behavior}

The titration solutions were deposited into Imhoff cones and allowed to settle for a total of four hours. The volume of floc was measured from the bottom of the imhoff cone at 15 minute increments for the first hour in an attempt to determine settling rate (Figure 3.6). The floc appeared to have finished settling within the first 15 minutes because the observed volumes decreased over time, rather than increasing as would be expected if settling was still occurring. This suggests that this exercise actually measured compression or compaction of the floc instead of settling. The floc in the control solution compressed the most, followed closely by floc from acetic acid solutions, then floc in malic solution, and floc from the citric solution showed the least compression over time. Between concentration levels of each acid, degree of compression increased as concentration decreased with the exception of the citric acid high solution. A very small volume of hydroxides 
formed from the citric high solution, and within the first hour no hydroxides settled to the bottom of the Imhoff cones.

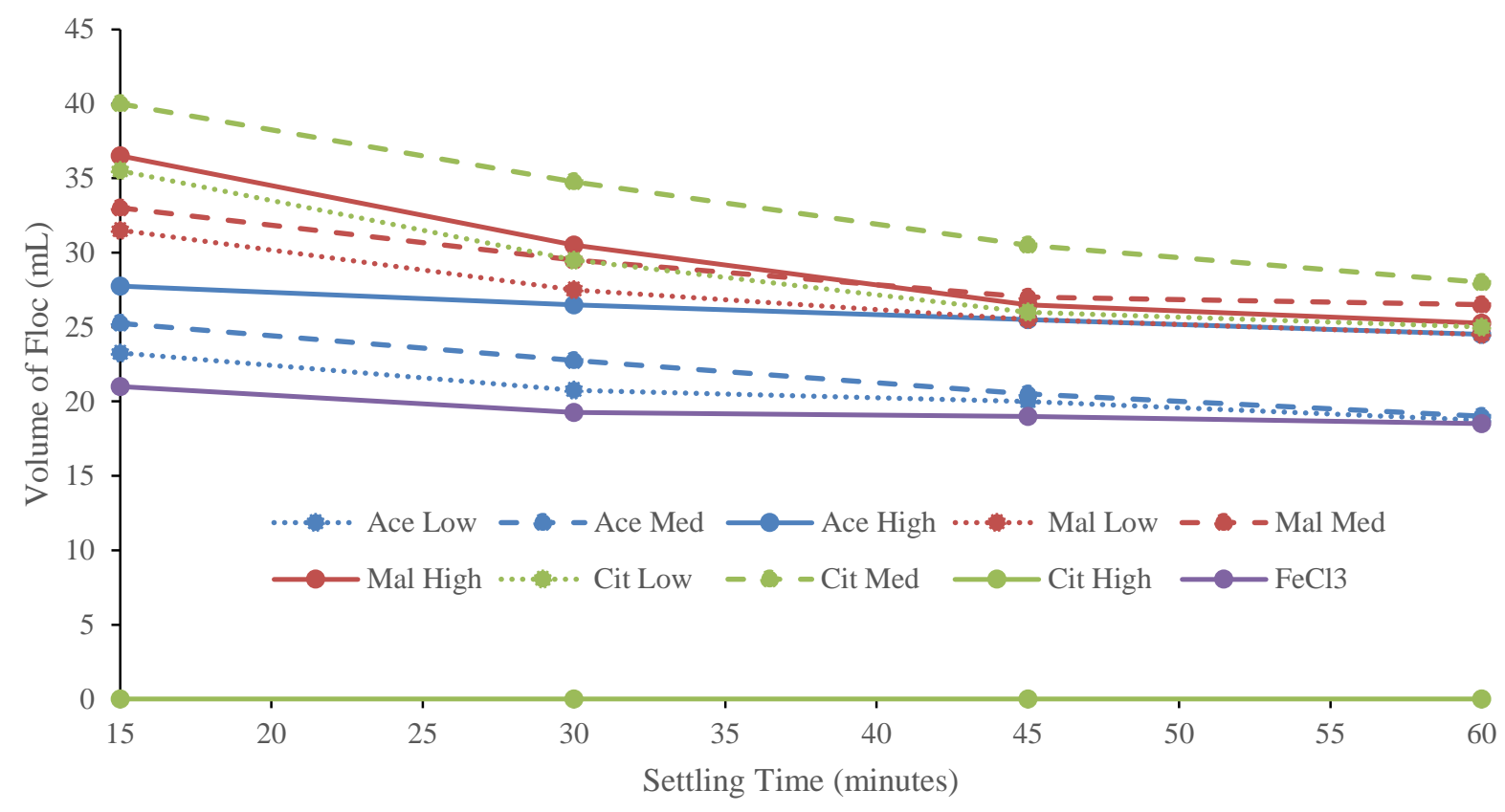

Figure 3.6. Hydroxide compression during the first hour of settling; represented by the settled volume of hydroxides in each treatment solution as a function of time the solids were allowed to settle in the Imhoff cones after formation.

The rate of hydroxide compression was determined by running analysis of covariance (ANCOVA) using time as a covariate for the effect of organic acid concentration on the volume of hydroxides formed. The rate of compression for the Fe only system $(-0.048 \mathrm{~mL} / \mathrm{hour})$ was drastically slower than the compression rate for all of the organic acid systems (Figure 3.7). 


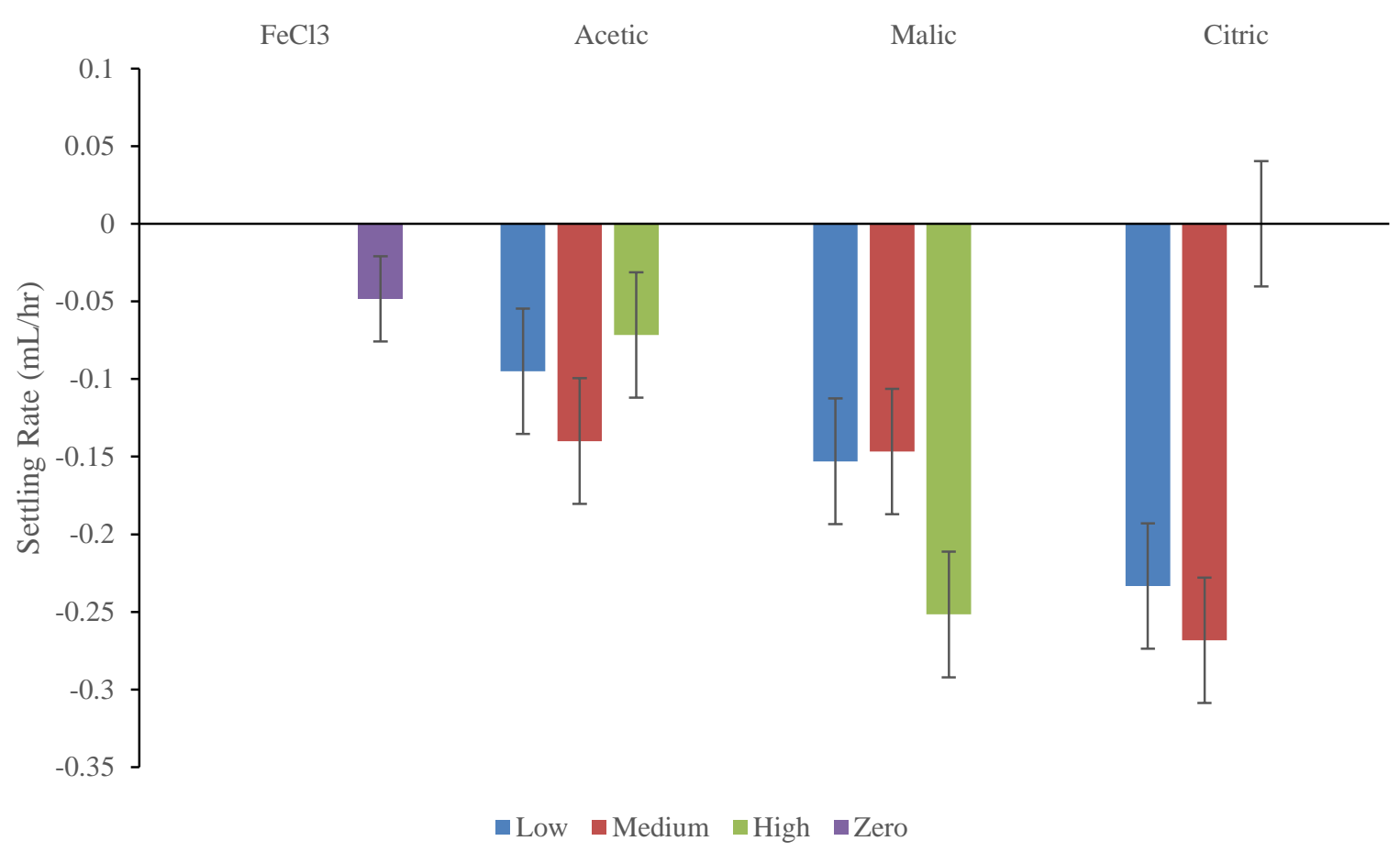

Figure 3.7. Rate of hydroxide compression in each organic acid and the control solutions (determined using time as a covariate in ANCOVA and comparing regression slopes for the three organic acids). Error bars represent standard error. $\mathrm{df}=3$.

Jones et. al's (2009a) argument that OM in solution hinders nucleation and aggregation could explain the marked lack of compression of organic matter treatments compared to the control treatment. If ligands occupy the sites on the surface of the hydroxides, the hydroxides are unable to aggregate and pack closely together.

These observed effects of OM on hydroxide behavior complicate the AMD treatment process. The finding that in the presence of organic matter, floc compresses less would necessitate longer floc settling times, significantly delaying the AMD treatment process and potentially increasing treatment costs. 
The main effect of concentration level was significant $(p=0.002)$ with respect to hydroxide volume. There was a trend associated with the main effect of organic acid in solution, but it was not statistically significant $(\mathrm{p}=0.077)$. The interaction between the organic acid present in solution and the concentration level was significant as well $(\mathrm{p}=\leq 0.0001)$ (Table 3.1). Generally, in the presence of organic matter, the volume of precipitate increased (Figure 3.8). The high concentration citric acid solution precipitated the smallest volume of hydroxides of the entire experiment; a negligible amount. The significance of the main effect of concentration and the interaction were likely driven by this very low hydroxide volume.

Table 3.1. ANOVA outputs for the main effects of the organic acid in solution, the concentration level of each organic acid, and the interaction between organic acid and concentration level on the final settled volume of hydroxides.

\begin{tabular}{llllll}
\hline Model & df & SS & MS & F Ratio & Prob $>$ F \\
\hline Organic Acid & 2 & 3257.3 & 1628.7 & 3.4 & 0.077 \\
Concentration & 2 & 128041.9 & 64020.9 & 13.5 & $0.0020^{*}$ \\
Organic Acid * Concentration & 4 & 468783.1 & 117195.8 & 24.7 & $<0.0001^{*}$ \\
\hline Error & 9 & 42734.6 & 4748.3 & 17.24 & $0.0001^{*}$ \\
\hline Total & 17 & 697507.4 & & & \\
\hline
\end{tabular}


Low $\square$ Medium $\quad$ High $\square$ Zero

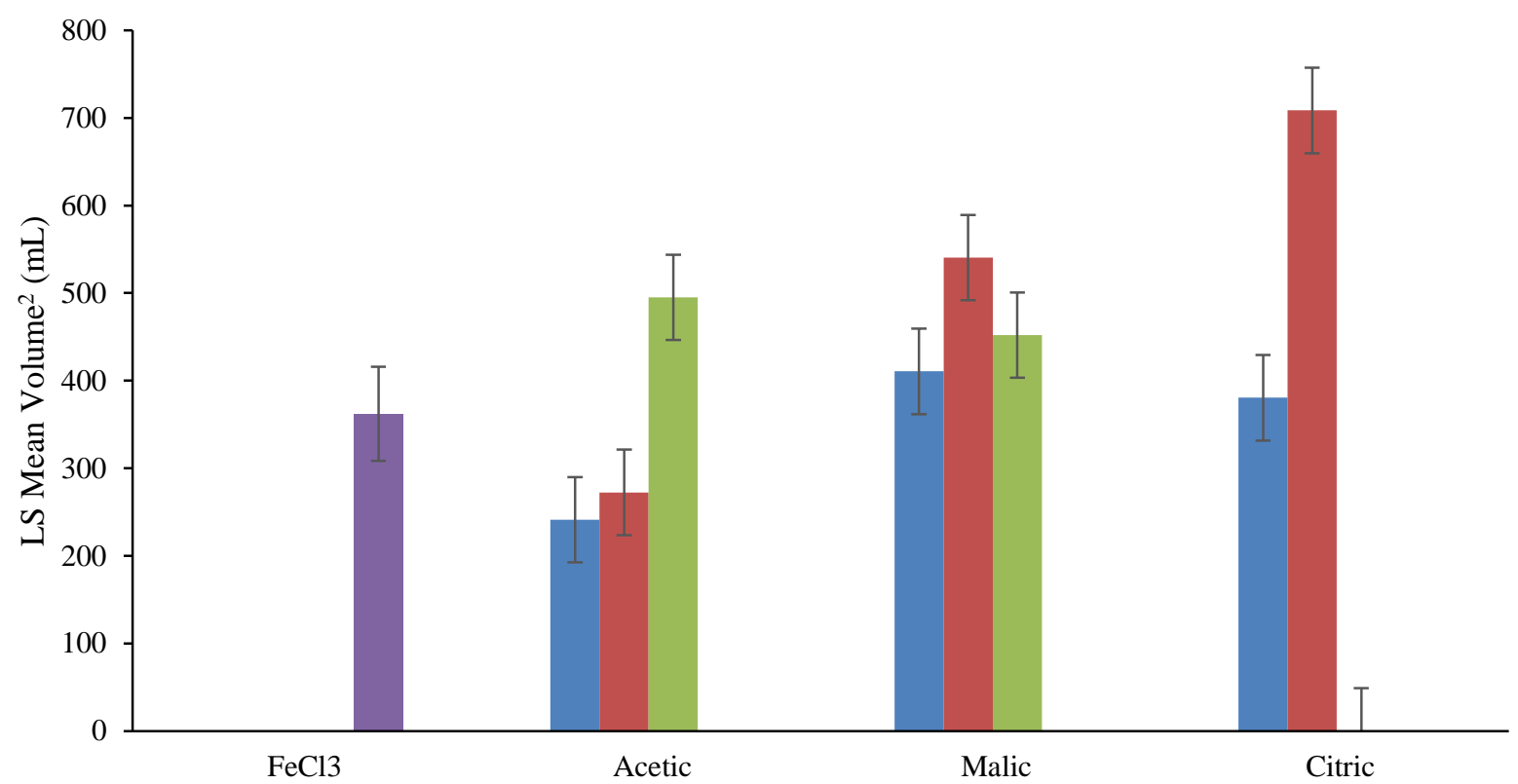

Figure 3.8. Least square means for the volumes $(\mathrm{mL})$ of settled hydroxide material (squared) in each organic acid treatment compared to the control $\left(\mathrm{FeCl}_{3}\right)$ Error bars represent standard error.

It was observed, but not quantified, that hydroxides formed in solutions with organic acids were more dispersed than those from the control $\left(\mathrm{FeCl}_{3}\right.$ only), suggesting poor crystal aggregation in floc formed in OM solutions. Floc was observed to float on the surface of the water and stick to the sides of the Imhoff cones. The results of the $\mathrm{pH} 10$ titrations showed elevated dissolved Fe concentrations at $\mathrm{pH}$ 7.5, which could explain the minimal volume of hydroxides in the high citric acid treatment.

The most obvious implication of increased hydroxide volume to AMD treatment is less settling and compression of hydroxides with high OM content in solution. This could mean a number of things for AMD treatment: hydroxides likely would need to settle in ponds longer extending the AMD treatment process and floc disposal costs may be larger because of the larger 
volume. Ultimately, the increased volume of hydroxides resulting from OM in solution translates to longer treatment times and higher treatment costs.

All three main effects (organic acid, concentration, and the interaction of the two) were statistically significant with respect to the final settled mass of iron hydroxides $(\mathrm{p}<0.0001)$. The main effect of concentration level was also significant (Table 3.2). The final settled masses of organic acid solutions were generally lower than those of the control solutions. This finding was not consistent with the finding that the presence of $\mathrm{OM}$ encouraged precipitation at lower $\mathrm{pH}$. If precipitation occurred sooner, it could be expected that hydroxide mass would increase.

Table 3.2. ANOVA outputs for the main effects of the organic acid in solution, the concentration level of each organic acid, and the interaction between organic acid and concentration level on the final settled mass of hydroxides.

\begin{tabular}{llllll}
\hline Model & df & SS & MS & F Ratio & Prob $>$ F \\
\hline Organic Acid & 2 & 28711020 & 14355510 & 42.2 & $<0.0001^{*}$ \\
Level & 2 & 35450587 & 17725294 & 52.1 & $<0.0001^{*}$ \\
Organic Acid * Level & 4 & 51371208 & 12842802 & 37.7 & $<0.0001^{*}$ \\
Error & 9 & 3062049 & 340227.7 & 38.7 & $<0.0001^{*}$ \\
Total & 17 & 108448995 & & & \\
\hline
\end{tabular}




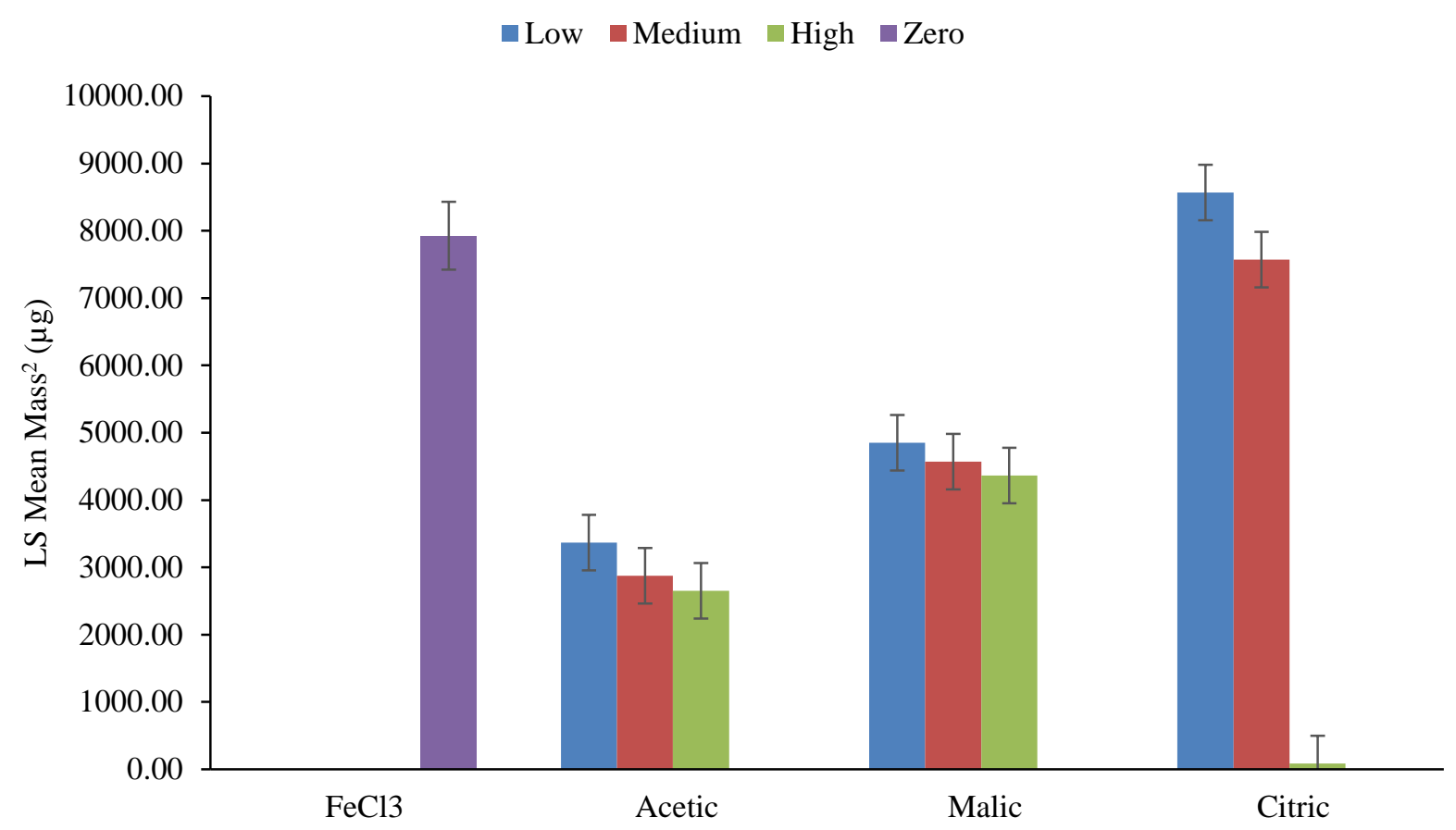

Figure 3.9. Least square means for the masses (mg) of settled hydroxide material (squared) in each organic acid treatment compared to the control $\left(\mathrm{FeCl}_{3}\right)$. Error bars represent standard error.

One explanation for the loss of hydroxide mass is that rapid precipitation favors the formation of colloidal suspensions (Skoog et al., 1992). Since precipitation occurred at lower pH in the presence of $\mathrm{OM}$, it is reasonable to assume that some hydroxide colloids formed. These colloidal hydroxides could passed through the $0.45 \mu \mathrm{m}$ filter papers. In order to verify that this phenomenon is occurring Fe concentration of the filtrate could be determined in future experiments. Another source of hydroxide mass loss could be hydroxides drying onto the Imhoff cones. While cleaning, iron residue was observed on the cones.

If mass of hydroxides decreased with organic matter content, and if the cost of hydroxide disposal was based on mass, AMD affected water containing organic matter would be easier and cheaper to treat since there would be fewer hydroxides to remove from the water before discharging treated water. In this sense, organic matter may be useful as an addition to decrease 
AMD floc mass. On the other hand however, if fewer Fe hydroxides precipitate out of a stream during the treatment phase, or if the hydroxides are colloidal suspensions; the Fe could remain mobile, allowing downstream transport. It is known that labile Fe often can be taken up by plants and other organisms, however increased organic matter in natural waters could make reaching the maximum contaminant level (MCL) for Fe more difficult.

Hydroxide density was calculated because it is a useful metric for AMD treatment. In general, the presence of OM resulted in decreased density compared to the control (Figure 3.10). The low densities were driven by the mass. The determination that in the presence of OM the floc had low density is consistent with the finding that the presence of OM decreased floc compaction. Decreased floc density would require longer settling times, thus increasing AMD treatment costs.

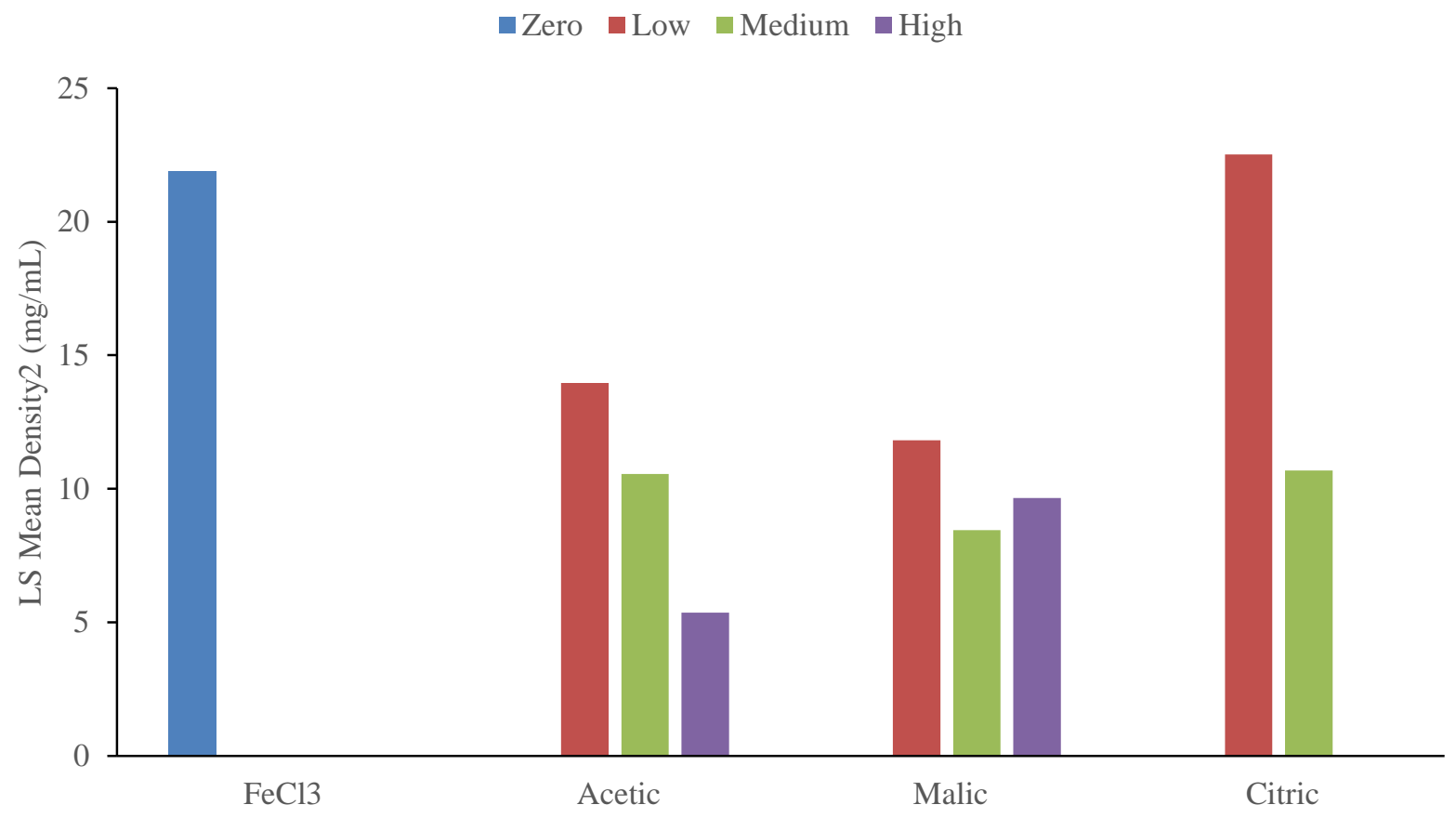

Figure 3.10. Density $\mathrm{mg} / \mathrm{mL}$ calculated from final settled mass and final settled volume data. 
The main effects of concentration and the interaction of organic acid and concentration did not have a significant effect on the percentage of amorphous hydroxides $(p=0.64$ and 0.79 , respectively). Data for the citric acid-high concentration system was not available because there was not enough dried hydroxide material to perform the extraction. The only main effect that was statistically significant with respect to the percent of amorphous Fe hydroxides was the organic acid used ( $\mathrm{p}=0.0083)$, but there was no clear trend (Figure 3.11).

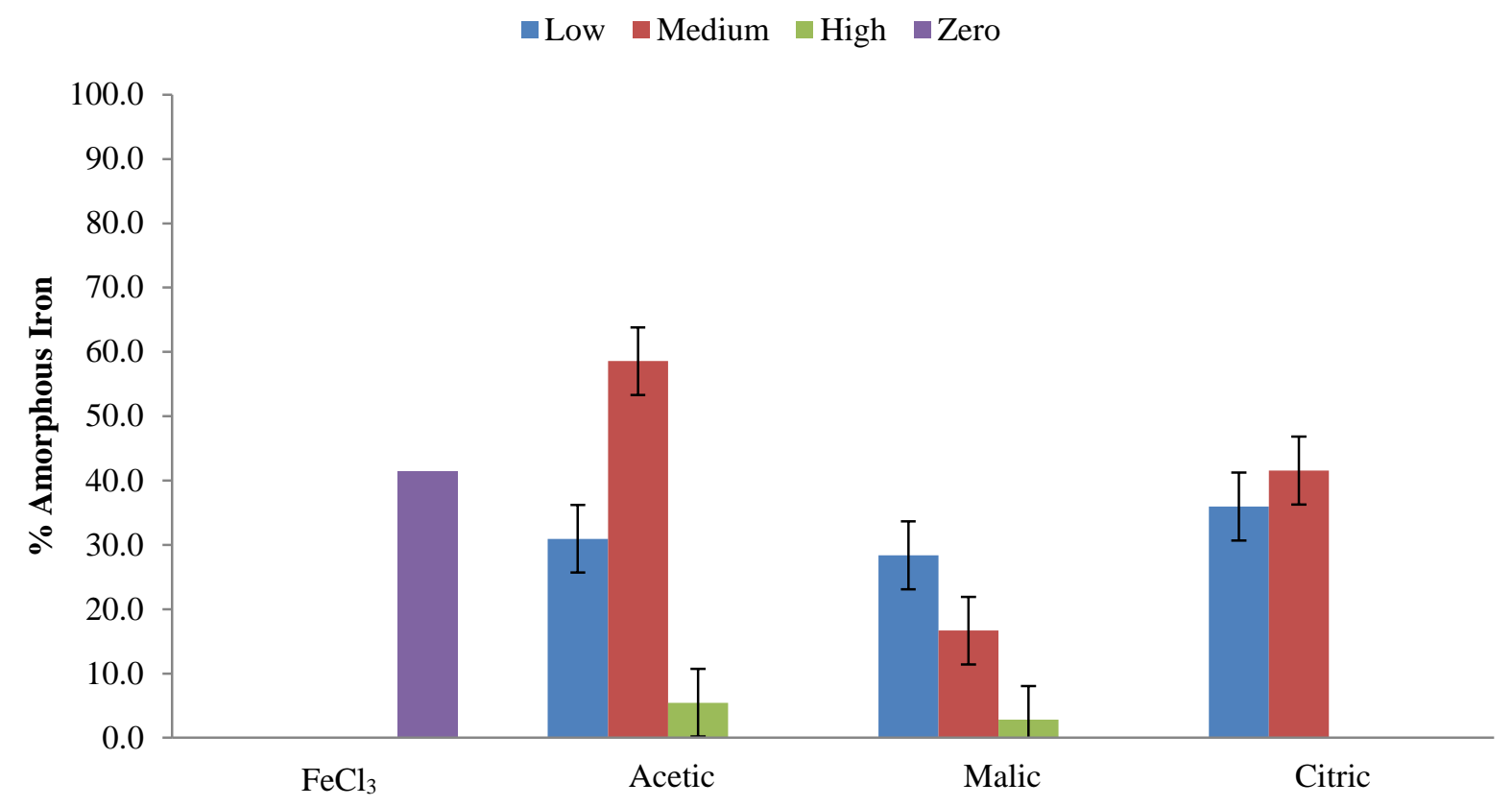

Figure 3.11. Percent of amorphous Fe hydroxides formed in the $\mathrm{FeCl}_{3}$, acetic, malic, and citric solutions. Error bars represent standard error.

The extraction method used in this experiment may not have been appropriate because a very small amount of hydroxide material was synthesized and it was difficult to scrape all hydroxide material off for the extraction. The method also was written for determining the amount of amorphous Fe hydroxides in 2 grams of soil, while this experiment extracted hydroxides alone; typically less than $0.5 \mathrm{~g}$. The floc compression, volume and density results of this study suggest 
that $\mathrm{OM}$ in solution interferes with aggregation between the hydroxides. The results of the Fe ammonium extraction would have been more consistent with these results if there was a trend of increased percent amorphous hydroxides in the presence of OM.

Disposal of crystalline Fe hydroxides would be optimal compared to amorphous hydroxides because they would likely be more massive, compress more, and take up less volume - plus they could have monetary value. Even with the relatively low \% amorphous values, it is highly unlikely that these synthetic Fe hydroxides were crystalline because the experimental conditions were not favorable for crystalline Fe hydroxides to form (i.e. high temperature, long duration of time, etc.) (Schwertmann and Cornell, 1991). 


\section{Chapter 4. Conclusions}

This study aimed to investigate the effects organic matter have on the formation and behavior of Fe hydroxides using simple carboxylic organic acids as analogs. This was evaluated by determining the soluble iron concentration, final settled hydroxide volume, final settled hydroxide mass, degree of hydroxide compression, and rate of hydroxide compression through a series of titration experiments with simple organic acids serving as analogs for organic matter. The selected organic acids included acetic acid, malic acid, and citric acid which were each evaluated at three different concentration levels. The results of these titration experiments suggest that the presence of organic matter does have a number of effects on iron hydroxides, however the effects are not driven by complexation alone.

The results of the dissolved iron concentration experiments suggested that in the presence of organic matter, iron hydroxide precipitation can occur at low $\mathrm{pH}$ and provided some evidence that complexation reactions occurred between the Fe and organic matter. One of the major findings of the hydroxide behavior experiments was that floc formed in the presence of organic matter has decreased density compared to floc formed in the control system. In the presence of organic matter, floc compressed less, but more rapidly than the control.

This research has several implications for active acid mine drainage treatment. The overarching implication is that the chemical processes involved in AMD treatment systems are complex and not fully understood, therefore treatment systems should be monitored more extensively and floc and water should be evaluated more thoroughly before discharge. If organic matter is present in AMD treatment systems, it might alter the amount of base required for neutralization. Knowledge of these effects could save mining operators money because they would be able to apply more appropriate base additions. Lastly, the presence of organic matter would 
necessitate longer floc retention times because the floc formed under those conditions had lower density and less compaction. This would delay the entire treatment process.

It is well known that organic matter is present in all natural surface waters and that microbial activity occurs in AMD. Given that information, it is reasonable to assume that organic matter is present in AMD treatment systems.

While it was apparent through this research that the presence of organic matter had an effect on iron hydroxides, the mechanism driving the effect is unclear. In order truly to understand the effects organic matter has on iron hydroxides, a number of further experiments could be conducted. Similar experiments could be carried out to evaluate the role different properties of organic matter have. Organic acids could be selected based on the number, type, structure or size of functional groups (i.e. molar volume), complexation constants, or pKa values. If all other variables were held constant, one might be able to draw a conclusion about which aspect drives the effect. Once some details of the mechanism or (mechanisms) driving the effects on hydroxides, a similar experiment could be carried out using a more realistic organic matter source such as humic acid, fulvic acid, or even stream samples with known concentrations of organic matter. It would also be interesting to characterize the hydroxides that form to determine their utility, and consider ways to repurpose them rather than disposal. 


\section{Literature Cited}

Benjamin, M. M.. Chemistry of Metals in Aqueous Systems in Water Chemistry. 2002. Waveland Press, Inc. Long Grove, IL. 362-463.

Bligh, M. W. and T. D. Waite. 2010. Formation, aggregation and reactivity of amorphous ferric oxyhydroxides on dissociation of Fe(III)-organic complexes in dilute aqueous suspensions. Geochimica et Cosmochimica Acta. 74: 5746-5762.

Brady, K. S., J.M. Bigham, W.F. Jaynes, and T.J. Logan. 1986. Influence of sulfate on Fe-oxide formation: comparisons with a stream receiving acid mine drainage. Clays and Clay Minerals. 34: 266-274.

Cornell, R. M., R. Giovanoli, and W. Schneider. 1989. Review of the hydrolysis of iron (III) and the crystallization of amorphous iron (III) hydroxide hydrate. Journal of Chemical Technology and Biotechnology. 46: 115-134.

Cornell, R. M., and U. Schwertmann. 2003. The Iron Oxides: Structure, Properties, Reactions, Occurences, and Uses. Wiley-VCH, Weinheim, Germany.

Cui, H., W. Ren, P. Lin, and Y. Liu. 2013. Structure control synthesis of iron oxide polymorph nanoparticles through an epoxide precipitation route. Journal of Experimental Neuroscience, 8, 7-8: 869-875.

Davies, H., P. Weber, P. Lindsay, D. Craw, B. Peake, and J. Pope. 2011. Geochemical changes during neutralization of acid mine drainage in a dynamic mountain stream, New Zealand. Applied Geochemistry, 26: 2121-2133. 
Dousma, D., and P. L. de Bruyn. 1976. Hydrolysis-Precipitation Studies of Iron Solutions: Model for Hydrolysis and precipitation from Fe(III) Nitrate Solutions. Journal of Colloid and Interface Science, 56. 3: 527-539.

Dousma, J., D. Den Ottelander, and P. L. de Bruyn. 1979. The influence of sulfate ions on the formation of iron (III) oxides. Inorganic Nuclear Chemistry, 41: 1565-1568.

Dyamczewski, Z., E.S. Kempa, and M.M. Sozanski. (1997). Coagulation as a structure-forming separation process in water and wastewater treatment. Water Science and Technology, 4:25-32.

Evangelou, V.P. 1998. Environmental Soil and Water Chemistry. John Wiley \& Sons, New York, NY.

Feng, W., and D. Nansheng. 2000. Photochemistry of hydrolytic iron (III) species and photoinduced degradation of organic compounds. A mini-review. Chemosphere, 41: 1137-1147.

Fujii, M., A. L. Rose, T. D. White, and T. Omura. 2009. Effect of divalent cations on the kinetics of Fe(III) complexation by organic ligands in natural waters. Geochimica et Cosmochimica Acta, 72: 1335-1349.

Harter, Robert D. and Ravendra Naidu. 1995. Role of metal-organic complexation in metal sorption by soils. p. 219-254 in Advances in Agronomy. Vol 55. Department of Natural Resources, University of New Hampshire, Durham, NH.

Hove, M., R. P. van Hille, and A. E. Lewis. 2008. Mechanisms of formation of iron precipitates from ferrous solutions at high and low pH. Chemical Engineering Science, 63: 1626-1635. 
Jackson, K. S., I. R. Jonasson, and G.B. Skippen. (1978). The nature of metals-sediment-water interactions in freshwater bodies, with emphasis on the role of organic matter. Earth Science Reviews, 14:97-146.

Johnson, D. B., and K. B. Hallberg. 2005. Acid Mine Drainage remediation options: a review. Science of the Total Environment, 338: 3-14.

Jones, A. M., R. N. Collins, J. Rose, and T. D. White, 2009a. The effect of silica and natural organic matter on the Fe(II)-catalysed transformation and reactivity of Fe(III) minerals. Geochimica et Cosmochimica Acta, 73: 4409-4422.

Jones, A. M., A. N. Pham, R. N. Collins, and T. D. White, 2009b. Dissociation kinetics of Fe(III)and $\mathrm{Al}(\mathrm{III})$-natural organic matter complexes at $\mathrm{pH} 6.0$ and 8.0 and $25^{\circ} \mathrm{C}$. Geochimica et Cosmochimica Acta, 73: 2875-2887.

Jones, D. S., C. Kohl, C. Grettenberger, L. N. Larson, W. D. Burgos, J. L. Macalady. 2015. Geochemical niches of iron-oxidizing acidophiles in acidic coal mine drainage. Applied and Environmental Microbiology, 81: 1242-1250.

Jonsson, J., J. Jonsson, and L. Lovgren. 2006. Precipitation of secondary Fe(III) minerals from acid mine drainage. Applied Geochemistry, 21:437-445.

King, Darrell, L., et al. 1974. Acid strip mine lake recovery. Water Pollution Control Federation, 46.10: 2301-2315.

Lahann, R. W. 1976. Surface charge variation in aging ferric hydroxide. Clays and Clay Minerals 24:320-26. 
Lenter, C. M., McDonald, L. M., Skousen, J. G., and P. Ziemkiewicz. 2002. The effects of sulfate on the physical and chemical properties of actively treated acid mine drainage floc. Mine Water and the Environment, 21: 114-120.

Lindsay, W. L. 1979. Chemical Equilibria in Soils. John Wiley \& Sons. New York.

Loeppert, R.H. and W.P. Inskeep. 1996. Iron. p. 639-664. In Methods of Soil Analysis. Part 3. Chemical Methods_-SSSA Book Series no. 5. Soil Science Society of America and

Nimick, D.A., Gammons, C.H., Parker, S.R., 2011. Diel biogeochemical processes and their effect on the aqueous chemistry of streams: A review. Chemical Geology, 283(1-2): 3-17.

Pedersen, H. D., D. Postma, R. Jakobsen, and O, Larsen. 2005. Fast transformation of iron oxyhydroxides by the catalytic action of aqueous Fe(II). Geochimica et Cosmochimica Acta, 69: 3967-3977).

Rashid, M. A. and J. D. Leonard. 1973. Modifications in the solubility and precipitation behavior of various metals as a result of their interaction with sedimentary humic acid. Chemical Geology, 11: 89-97.

Rosenbaum, Walter A., 2011. Environmental Politics and Policy. 8th Edition. CQ Press, Washington, DC.

Ross, G. J. and C. Wang, 1993. Extractable Al, Fe, Mn, and Si. In: M. R. Carter (ed.) Soil Sampling and Methods of Analysis.

Sheldrick, B. H. 1984. Acid Ammonium Oxalate Extractable Fe and Al (Mn and Si if Desired). In: Analytical Methods Manual. Ottawa: Research Branch Agriculture Canada. Section 84$011 ; 11 / 1-11 / 3$. 
Schwertmann, U., J. M. Bigham, and E. Murad. 1995. The first occurrence of schwertmannite in a natural stream environment. European Journal of Mineralogy, 7: 547-552.

Schwertmann, U. and R.M. Cornell. 1991. Iron Oxides in the Laboratory. VCH Publishers, New York, NY.

Scwertmann, U. and R.M. Taylor. 1989. Iron Oxides. P. 379-438. In J.B. Dixon and S.B. Weed (ed.) Minerals in Soil Environments. SSSA, Madison, WI.

Sholkovitz, E. R., and D. Copeland. 1980. The coagulation, solubility, and adsorption properties of $\mathrm{Fe}, \mathrm{Mn}, \mathrm{Cu}, \mathrm{Ni}, \mathrm{Cd}, \mathrm{Co}$, and humic acids in a river water. Pergamon Press Ltd.

Sillén, L. G., A. E. Martell, and J. Bjerrum. 1964. Stability constants of metal-ion complexes. Second Edition. Chemical Society: London, England.

Skoog, D. A.; West, D. M.; Hollar, J. F. 1992. Fundamentals of Analytical Chemistry, Sixth Edition. Saunders College Publishing: New York, NY.

Skousen, J., Simmons, J., McDonald, L. M., and P. Ziemkiewicz. 2002. Acid-Base Accounting to predict post-mining drainage quality on surface mines. Journal of Environmental Quality, 31(6): 2034-2044.

Sparks, Donald L., 2003. Environmental Soil Chemistry. Academic Press, San Diego, CA.

Stajdohar, J., M. Ristic, and S. Music. 2013. The effect of experimental conditions on the microstructure of hematite particles precipitated by the forced hydrolysis of $\mathrm{FeCl}_{3}$ solutions. Journal of Molecular Science. 1044: 290-298.

Stumm, W and J.J. Morgan. 1996. Photochemical Properties. p. 726-759. In W. Stumm and J.J. Morgan. Aquatic Chemistry. Wiley Interscience. New York, NY. 
Trumm, D. Selection of active and passive treatment systems for AMD - Flow charts for New Zealand conditions. 2010. New Zealand Journal of Geology and Geophysics, 53(2-3): 195210.

United States Energy Information Administration. Annual Energy Review 2011. Web. $<$ http://www.eia.gov/totalenergy/data/annual/>

Vandenberghe, R.E., E. DeGrave, C. Landuydt, and L.H. Bowen. 1990. Some aspects concerning the characterization of iron oxides and hydroxides in soils and clays. Hyperfine Interactions, 53: 175-196.

Waite, T. D., \& Morel, F. M. 1984. Photoreductive dissolution of colloidal iron oxides in natural waters. Environmental science \& technology, 18(11): 860-868.

Younger, P.L., S.A. Banwart, and R.S. Hedin. 2002. Mine Water: Hydrology, Pollution, Remediation. Kluwer Academic Publishers, Norwell, MA.

Zboril, R., M. Mashlan, and D. Petridis. 2002. Iron(III) oxides from thermal processes - synthesis, structural and magnetic properties, Mossbauer spectroscopy characterization, and applications. Chemical Matter, 14: 969-982 


\section{Appendix 1}

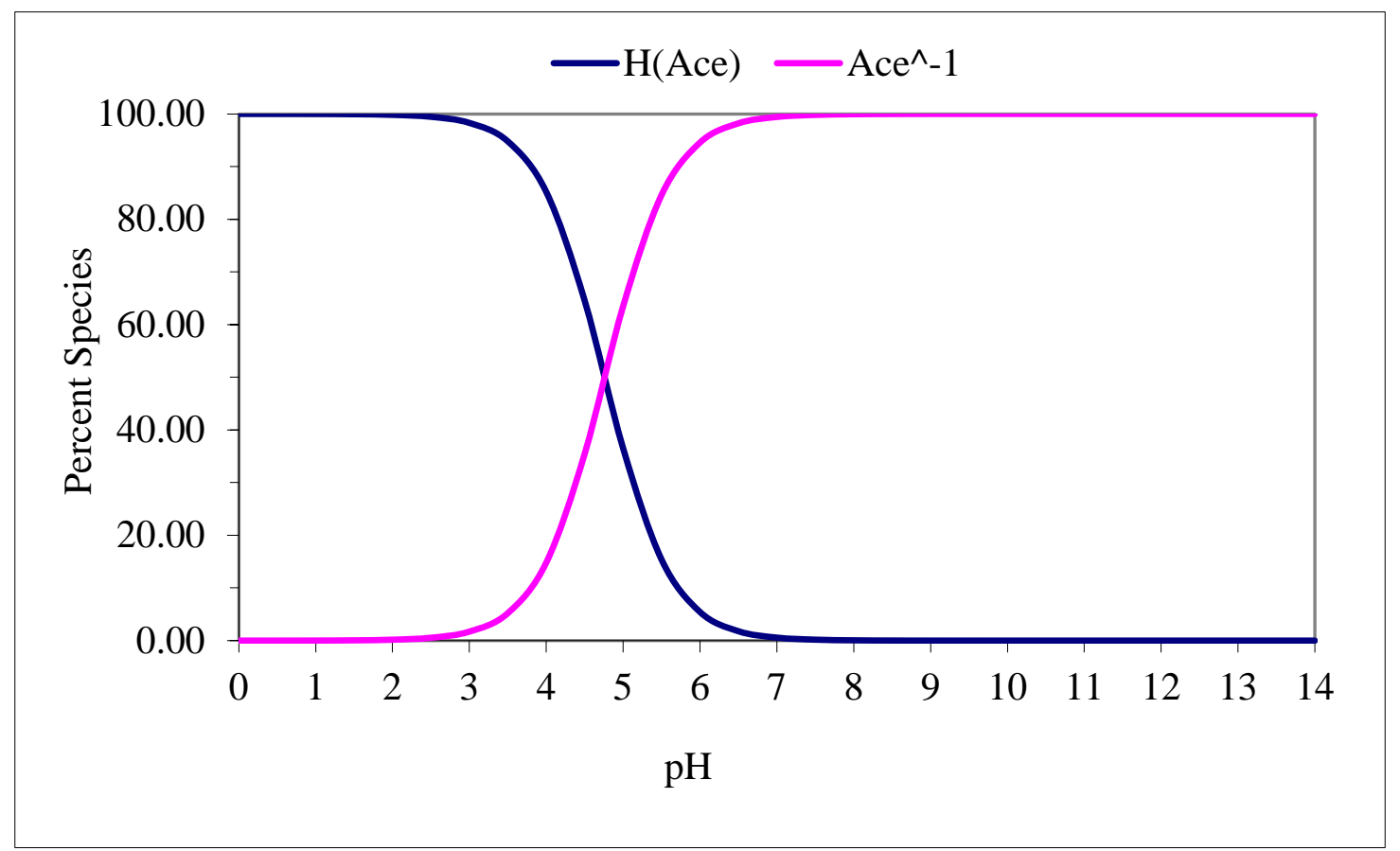

Figure A1.1. Fractional concentrations of acetic acid as a function of solution $\mathrm{pH}$ (Sillen et al, 1964). 


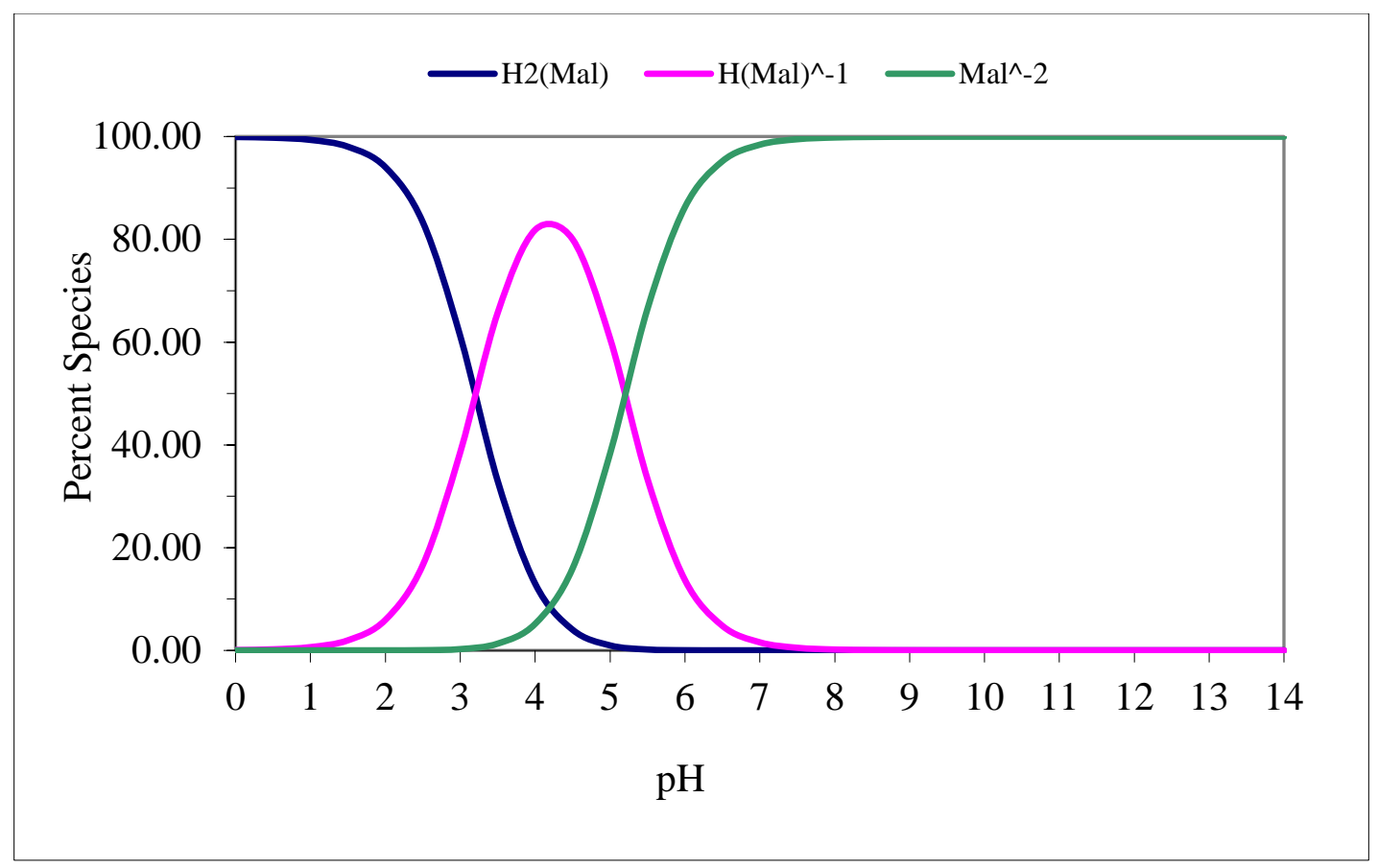

Figure A1.2. Fractional concentrations of malic acid as a function of solution pH (Sillen et al, 1964).

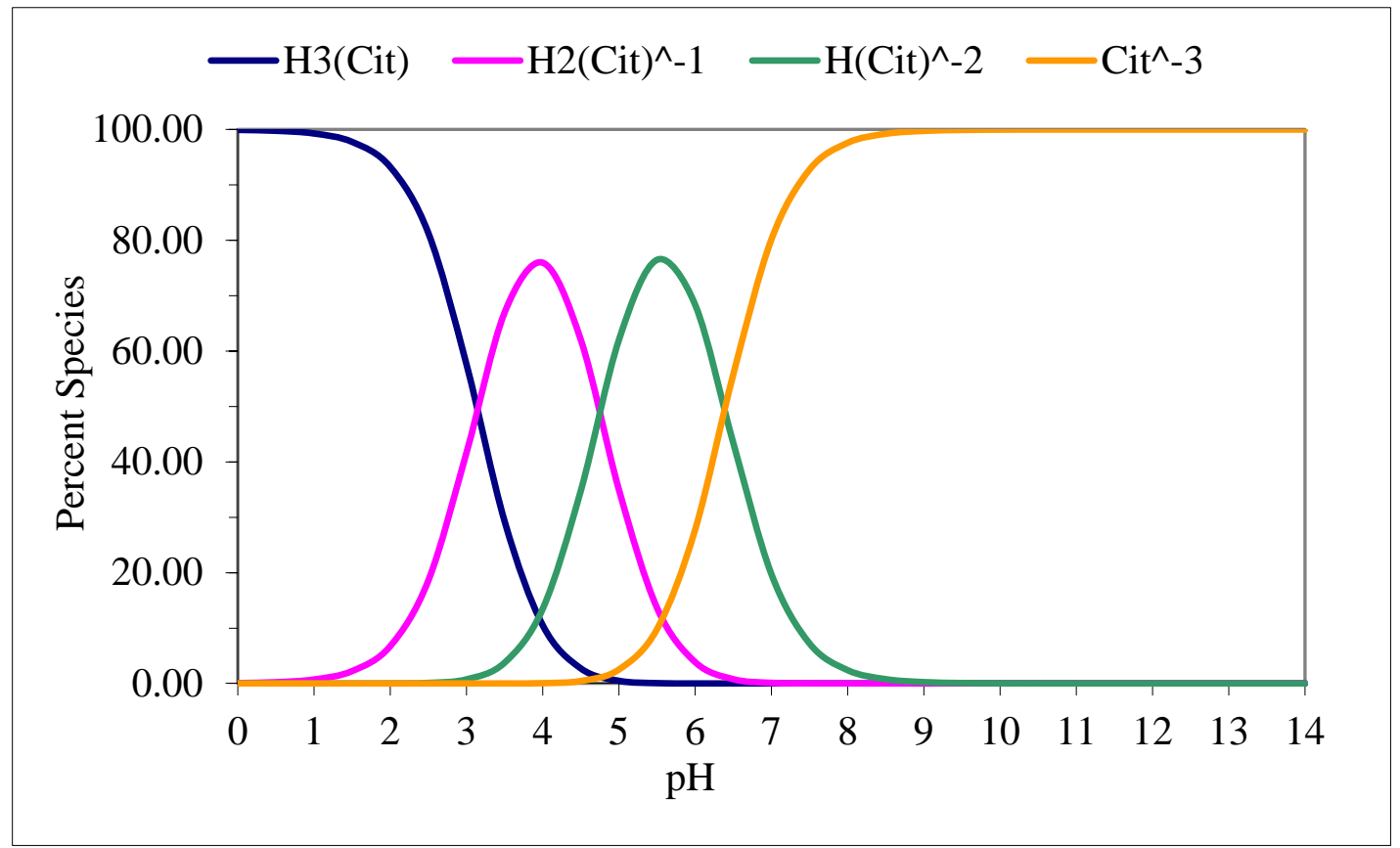

Figure A1.3. Fractional concentrations of citric acid as a function of solution $\mathrm{pH}$ (Sillen et al, 1964). 